\title{
FI Catalyst for Polymerization of Olefin
}

\author{
S. Damavandi, S. Ahmadjo, R. Sandaroos and G.H. Zohuri
}

Additional information is available at the end of the chapter

http://dx.doi.org/10.5772/46187

\section{Introduction}

Since the pioneering by Karl Ziegler and Giulio Natta in the early 1950's on the polymerization of simple olefins, there has been intense interest in the application of early transition metal catalysts for the selective polymerization of inexpensive olefins. Following to Ziegler-Natta catalysts [1], metallocene catalysts were discovered in the late 1980's and resulted in numerous industrial processes for improving the properties of polyolefinic materials along with performance parameters. This field has been remarkably renewed with the use of catalysts based on early transition metals metallocene [2]. Development of new catalysts with transition metals has played a substantial role in the fast-growing polyolefins industry. Improvement of new, better performing, less costly polyolefins has often been a result of catalyst development. However, polymerization processes of olefins, beside the requirement of higher activity catalyst to control the particle size, particle size distribution, and morphology of the resultant polyolefin are quite important. In the other words, success in these developments requires an appropriate integration of catalyst selections with reactor type and process parameters [3-5].

As is well-known, most polyolefinic materials are produced using transition metalcatalyzed olefin polymerization technology. While the multisited heterogeneous ZieglerNatta catalysts represented by $\mathrm{MgCl}_{2}$-supported $\mathrm{TiCl}_{4}$ catalysts currently dominate the market, molecular catalysts (single-site catalysts) represented by group 4 metallocene catalysts and constrained geometry catalysts (CGCs) are gaining an increasing presence in the market (Figure 1) [4-9].

As DFT (Density Functional Theory) calculations performed on a model metallocene catalyst $\mathrm{H}_{2} \mathrm{SiCp}_{2} \mathrm{ZrMe}^{+}$for ethylene polymerization (Figure 2) suggested that ethylene polymerization is a process that involves intense electron exchange between a ligand and a metal [10]. Accordingly and following the great success of the metallocene catalysts, significant efforts have been directed toward the discovery and application of new, highly active, single-site catalysts (post-metallocene catalysts) [10,11]. 


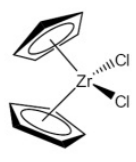

(a)

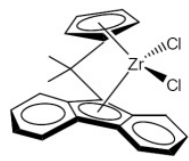

(c)

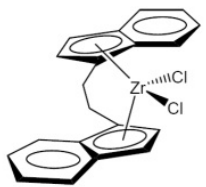

(b)

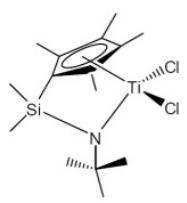

(d)

Figure 1. Metallocene catalysts for olefin polymerization: (a) $\mathrm{Cp}_{2} \mathrm{ZrCl}_{2}$; (b) $r a c-\mathrm{Et}(\mathrm{Ind})_{2} \mathrm{ZrCl}_{2}$; (c) $\mathrm{iPr}(\mathrm{Flu})(\mathrm{Cp}) \mathrm{ZrCl}_{2}$; (d) Constrained geometry catalyst (CGC) [10].

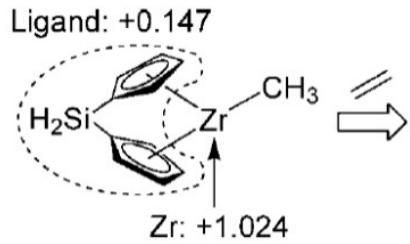

Ligand: +0.071

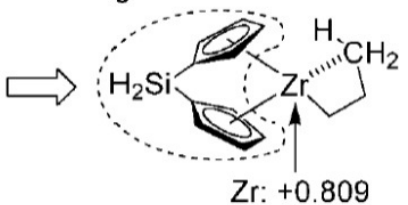

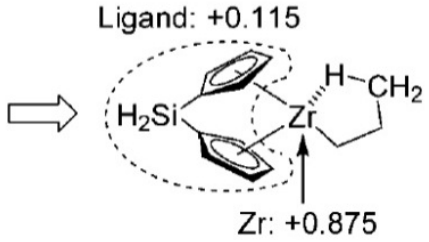

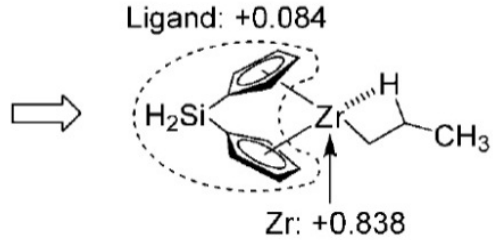

Figure 2. Calculated Charges of the ligand and $\mathrm{Zr}$ metal of a model metallocene catalyst for ethylene polymerization (DFT calculations) [10].

These research efforts have led to the introduction of quite a few high-activity single-site catalysts based on both early and late transition metal complexes with various ligand environments [12-18]. In association with appropriate cocatalysts, many of these catalysts show ethylene polymerization activities that are superior or comparable to those seen with early group 4 transition metals metallocene catalysts. These post-metallocene catalysts can produce a wide array of distinctive polymers (e.g., hyper-branched PEs, ethylene-methyl acrylate copolymers, monodisperse poly(1-hexene)s, and block copolymers based on $\alpha$ olefins), many of which were inaccessible using metallocene catalysts [3,16-24].

Since the ligand structure has a central role in determining the activity as well as the stereospecifity of these types of catalysts, and as shown in Figure 2, flexible electronic nature of a ligand is a key requirement for achieving high activity, the research based on the ligand oriented catalyst design concept has resulted in the discovery of a number of highly active 
catalysts for the polymerization of ethylene, which include: phenoxy-imine ligand early transition metal complexes (FI catalysts), pyrrolide-imine ligand group 4 transition metal complexes (PI catalysts), indolide-imine ligand Ti complexes (II catalysts), phenoxy-imine ligand group 4 transition metal complexes (IF catalysts), phenoxy-ether ligand Ti complexes (FE catalysts), imine-pyridine ligand late transition metal complexes (IP catalysts), and tris(pyrazolyl) borate ligand Ta complexes (PB catalysts) (Figure 3) [20,26-30].

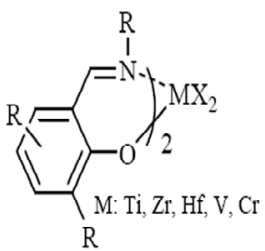

FI Catalysts

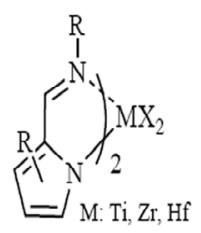

PI Catalysts

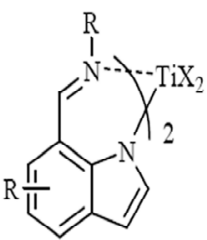

II Catalysts

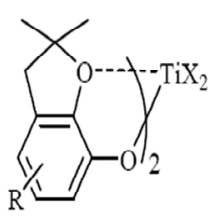

FE Catalysts

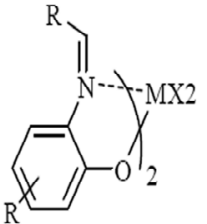

M: $\mathrm{Ti}, \mathrm{Zr}$

IF Catalysts

Figure 3. Development of highly active single-site ethylene polymerization catalysts [20].

In particular, bis(phenoxy-imine) group 4 metal catalysts, developed by Fujita [19-21] caused a new revolution in the field of catalytic olefin polymerization. These complex catalysts exhibit unique characteristics for production of new polymers that are not prepared by conventional Ziegler-Natta catalysts, as well as by ordinary metallocene-type catalysts [16]. The key feature of these complexes is the incorporation of nonsymmetric bidenate or tridentates ligands that possess electronically flexible properties (e.g., phenoxycyclopentadienyl, phenoxy-imine, phenoxy-ether, phenoxy-pyridine, pyrrolide-imine, and indolide-imine). These complexes can typically combine with appropriate cocatalysts to form highly active catalysts for the polymerization of ethylene. Among these new complexes, bis(phenoxy-imine) early transition metal complexes (named FI Catalysts) are particularly versatile for olefin polymerization when activated (Figure 4) [20,21].

Although a large number of families of high-performance single-site catalysts have been developed thus far, improvements in some aspects of catalytic performance (e.g., temperature stability, precise control of chain transfer, comonomer sequence distribution control, precise control of polymer stereochemistry, and the ability to incorporate sterically encumbered monomers and polar monomers) are still required to achieve both greater control over polymer microstructures and extension of generic polyolefinic materials by introducing new monomer combinations [31].

\section{Characteristics of FI catalysts}

In 1997, researchers at Mitsui Chemicals introduced phenoxy-imine [O-N] ligand early transition metal complexes (now known as FI catalysts) for the controlled polymerization and copolymerization of olefinic monomers [30]. Depending on the ligand design, the catalysts show different behaviors in ethylene and propylene polymerization, and the 
ligands strongly influence catalyst parameters such as activity, polymerization mechanism, and polymer properties including molecular weight. Extensively, FI catalysts, can polymerized ethylene with high efficiency, independent of the transition metals that are employed (Ti, Zr, Hf, etc.), showing the notable ability of phenoxy-imine ligands for efficient ethylene insertion.

The electronically flexible nature of the phenoxy-imine ligands may be responsible for these superior results. FI catalysts have the following structural and electronic features resulting in unique polymerization catalysis as well as formation of distinctive polymers [31-34].

$\mathrm{TiCl}_{4} / \mathrm{R}_{3} \mathrm{Al}, \mathrm{TiCl}_{3} / \mathrm{R}_{2} \mathrm{AlCl}$

$\mathrm{TiCl}_{4} / \mathrm{R}_{3} \mathrm{Al} / \mathrm{MgCl}_{2}$ or $\mathrm{SiO}_{2}$

Zlegler-Natta Catalysts

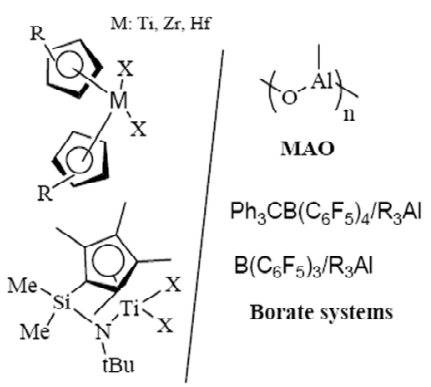

Metallocene Catalysts

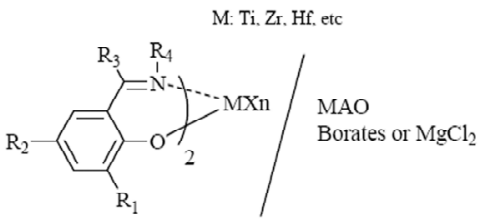

FI Catalysts

Figure 4. The progression of catalyst discovery, conventional olefin catalysts and FI catalyst [20,21].

\subsection{Structure of FI catalysts}

Since an FI catalyst contains two bidentate nonsymmetric phenoxy-imine ligands, it can potentially display five isomers from a to e (Figure 5) arising from the coordination modes of ligands in an octahedral configuration. X-ray analysis has established that, in the solid state, an FI catalyst normally exists as the isomer a, meaning, it has a trans-O, cis- $\mathrm{N}$, and cis$\mathrm{Cl}$ arrangement, and thus $\mathrm{C}_{2}$ symmetry [35]. The $\mathrm{C}_{2}$-symmetric nature implies that the catalyst may be an isospecific catalyst for propylene polymerization [35].

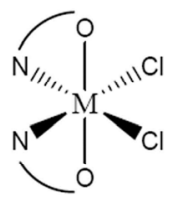

a

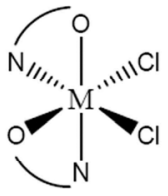

b

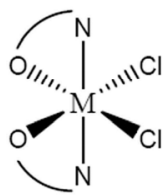

c

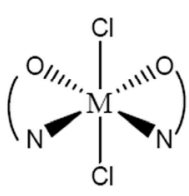

$\mathrm{d}$

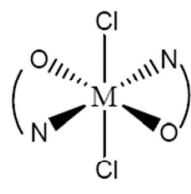

e

Figure 5. Possible isomers for FI catalysts. a) $\mathrm{N}$-cis, $\mathrm{O}$-trans, $\mathrm{Cl}$-cis, $\mathrm{C}_{2}$ symmetry b) $\mathrm{N}$-cis, $\mathrm{O}$-cis, $\mathrm{Cl}$-cis, $\mathrm{C}_{1}$ symmetry c) $\mathrm{N}$-trans, O-cis, Cl-cis, $\mathrm{C}_{2}$ symmetry d) N-cis, O-cis, Cl-trans, $\mathrm{C}_{2}$ symmetry e) N-trans, Otrans, Cl-trans, $\mathrm{C}_{2}$ symmetry [20,35].

When FI catalysts possess extremely bulky groups on the imine-Ns $\left(N-\mathrm{C}_{6} \mathrm{H}_{3}-2,6-\mathrm{R}^{2}, \mathrm{R}: \mathrm{Me}, i-\right.$ $\mathrm{Pr})$, they can adopt a cis-O, trans- $\mathrm{N}$ and cis- $\mathrm{X}(\mathrm{X}=\mathrm{O}-\mathrm{i}-\mathrm{Pr})$ arrangement. Any further increase in the steric bulk of the $\mathrm{R}^{1}$ substituent $\left(\mathrm{N}-\mathrm{C}_{6} \mathrm{H}_{3}-2,6-\mathrm{Ph}_{2}\right.$ or $\mathrm{N}-\mathrm{CHPh}$ ) forces one of the $\mathrm{N}-\mathrm{Ti}$ 
bonds to become dissociated, resulting in a five-coordinated complex [36]. However, FI catalysts generally exist as a mixture of isomer a, which is normally predominant (trans-O, cis- $\mathrm{N}$, and cis- $\mathrm{Cl}$ arrangement: $\mathrm{C}_{2}$ symmetry), and isomer $\mathbf{b}$ (cis- $\mathrm{O}$, cis- $\mathrm{N}$, and cis- $\mathrm{Cl}$ arrangement: $\mathrm{C}_{1}$ symmetry $[36,37]$. These isomers are often fluxional and can mutually transform each other on a nuclear magnetic resonance (NMR) time scale [35].

In the other words, among the five possible isomers (Figure 5), the crystallographically determined structures of FI catalysts, adopt a configuration in which the shortest M-O bonds ( $\mathrm{M}=$ group 4 transition metal) are positioned trans to each other, and the nitrogen atoms and $\mathrm{Cl}$ ligands are in cis-positions, displaying overall $C_{2}$ symmetry (Figure 4a) [34,38]. In this "ordinary" $C_{2}$ symmetric FI catalyst, the two imine-N's are positioned in a plane defined by a metal $\mathrm{M}$ and two $\mathrm{Cl}$ ligands, and therefore, substituents on the imine- $\mathrm{N}^{\prime} \mathrm{s}\left(\mathrm{R}^{1}\right)$ are on a plane at the backside of the X-M-X moiety, while substituents ortho to the phenoxy$\mathrm{O}^{\prime} \mathrm{s}\left(\mathrm{R}^{2}\right)$ are located above and below the X-M-X moiety (Figure 6). Since the X-M-X moiety becomes a reaction site after activation, these $R^{1}$ and $R^{2}$ substituents have the most pronounced effects on polymerization reactions, but each of the substituents work in a different manner due to their particular spatial arrangements [38].

As discussed, an important feature of these complexes is that the chlorines occupy mutually cis coordination sites. This is potentially significant for generating efficient polymerization active centers since a crucial requirement for a highly-active catalyst is to have a pair of cis located sites for olefin polymerization [38].

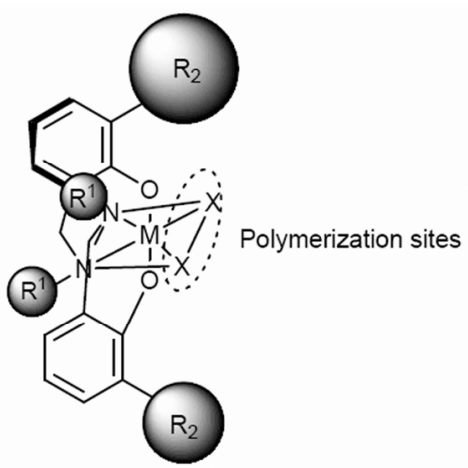

Figure 6. Molecular structures of the FI catalysts [39].

Nevertheless, the DFT calculations suggest that the $\mathrm{Zr}-\mathrm{N}$ bonds that lie on the same plane as the polymerization sites expand and shrink according to the reaction coordinate of the ethylene insertion (2.23-2.34 ̊), while the $\mathrm{Zr}-\mathrm{O}$ bond length remains virtually unchanged (Figure 7). From studying these results, we believe that this variable $\mathrm{Zr}-\mathrm{N}$ bond length (which facilitates a smooth and flexible electron exchange between the metal and the ligands) and the cis located active sites, as well as the electronically flexible nature of the phenoxy-imine ligands, are responsible for the high polymerization activities of FI catalysts $[38,39]$. 
In general, FI ligands can be obtained in practically quantitative yields by the Schiff-base condensation of ortho-hydroxy aromatic aldehydes or ketones and primary amines.

These phenol derivatives and amines are easily synthesized, and thus have a rich inventory of commercially available compounds. Therefore, FI catalysts have a wide range of catalyst design possibilities, which is the most important feature of FI catalysts.

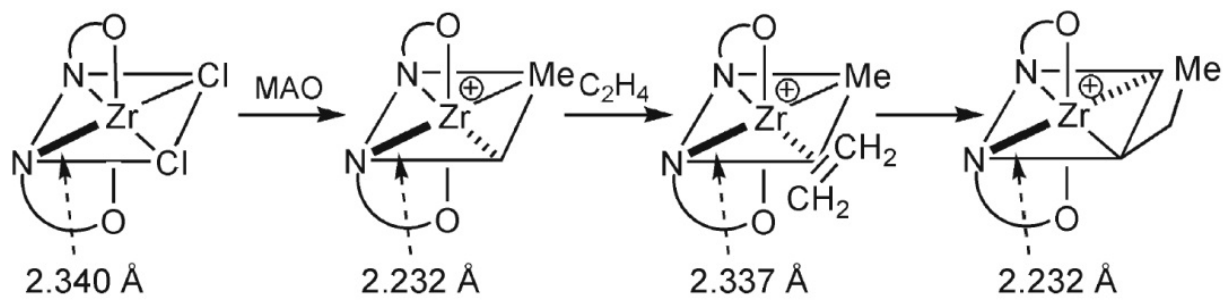

Figure 7. DFT calculation results for ethylene polymerization with FI catalyst/MAO [38].

As a result of this feature, FI catalysts have enormous and diverse ligand structures with a wide variety of substituents, including $\mathrm{O}, \mathrm{S}, \mathrm{N}, \mathrm{P}$ and halogen-based functional groups. This enormous structural diversity of FI catalysts has given rise to unprecedented olefin polymerization catalysis and unique polymer formation [34,35,37].

\subsection{Electronic characteristics of FI catalysts}

In general, the discovery of new olefin polymerization catalysts seems to be a time-intensive, trial-and-error process, with no guarantee of success. However, theoretical calculations on ethylene polymerization with a metallocene catalyst have provided clues about how to design highly active catalysts. Polymerization olefin catalyst components has been depicted in Figure 8 including a metal, ligand(s), a growing polymer chain, a coordinated olefin, and a cocatalyst [40-42] .

As can bee seen in Figure 8, FI catalysts are heteroatom [O-, N] coordinated early transition metal complexes, which makes FI catalysts different from group 4 transition metals metallocene catalysts that possess cyclopentadienyl (Cp) carbanion-based ligands. Because of the coordination of heteroatom-based $\left[\mathrm{O}^{-}, \mathrm{N}\right]$ ligands that are more electron withdrawing than $\mathrm{Cp}$ carbanion-based ligands, the catalytically active species originating from FI catalysts possess a highly electrophilic nature relative to the active species derived from group 4 transition metals metallocene catalysts [39].

As explained before, DFT calculations using a cationic metallocene complex $\left(\mathrm{H}_{2} \mathrm{SiCp}_{2} \mathrm{ZrMe}^{+}\right)$as a model suggest that olefin polymerization is a process that involves intense electron exchange between a ligand and a metal. Since all transition metals (even $\mathrm{Mn}$ and $\mathrm{Fe}$ ) potentially possess the capability of olefin insertion, it is believed that ligands with an electronically flexible nature are a prime requisite for achieving high activity. Therefore, the combination of a transition metal and electronically flexible ligand(s) can yield a highly active olefin polymerization catalyst. Electronically flexible ligands 
typically possess well-balanced electron donating and withdrawing properties, indicated by a small energy gap between HOMO (the highest occupied molecular orbital) and LUMO (the lowest unoccupied molecular orbital). Therefore, they are capable of receiving electrons from the coordinating olefin through the metal atom and of releasing electrons whenever required to expedite the olefin insertion process. As a result, it can be realized that it is the ligands that play the predominant role in polymerization catalysis among the typical components of the catalyst, and that electronically flexible ligands combined with transition metals form high-activity catalysts when activated as long as the potentially active species possesses an appropriate electron deficiency (10- to 16-electron species) as well as a pair of available cis-located sites for polymerization. According to the fact, many researches have been devoted to ligand-oriented catalyst design in an attempt to discover highly active catalysts [38,39].

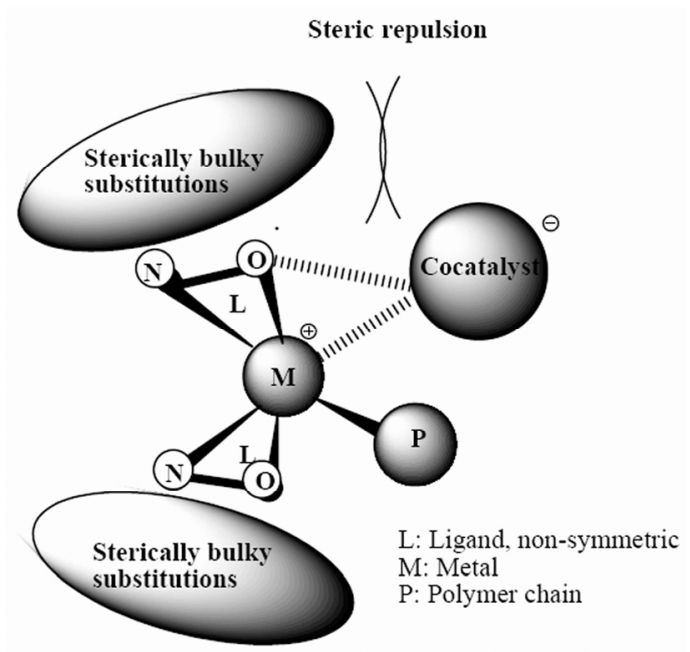

Figure 8. Polymerization components [42].

FI catalysts have another distinctive feature verses metallocenes, that is, M-ligand bonding characteristics. The presence of FI ligands with heteroatom donors renders the complex more electrophilic, a requirement for an active olefin polymerization catalyst, as supported by DFT calculations, which demonstrated that the Mulliken charge at the metal center (in $\mathrm{au})$ in three cationic species increases in the following order, $\left(\mathrm{C}_{5} \mathrm{H}_{5}\right)_{2} \mathrm{TiMe}^{+}<\mathrm{CGC}$ $\left(\mathrm{Me}_{2} \mathrm{Si}\left(\mathrm{C}_{5} \mathrm{Me}_{4}\right)-(t \mathrm{Bu}-\mathrm{N}) \mathrm{TiMe}^{+}\right)<\left(\mathrm{Ph}-\mathrm{N}=\mathrm{CH}_{-} \mathrm{C}_{6} \mathrm{H}_{3}-2-\mathrm{O}-3-t \mathrm{Bu}\right)_{2} \mathrm{TiMe}^{+}$(Figure 9) $[40,41]$.

Furthermore, DFT calculation revealed that anionic phenoxy-imine chelate ligand possess a smaller energy gap between HOMO and LUMO than a $\mathrm{Cp}$ ligand $\left(\mathrm{C}_{5} \mathrm{H}_{5}{ }^{-}\right)$and thus presumably display electronically more flexible properties than the $\mathrm{Cp}$ ligand (Figure 10) [42]. Small energy gap between HOMO and LUMO represents well-balanced electrondonating and withdrawing properties which are anticipated to expedite ethylene polymerization process [42]. 


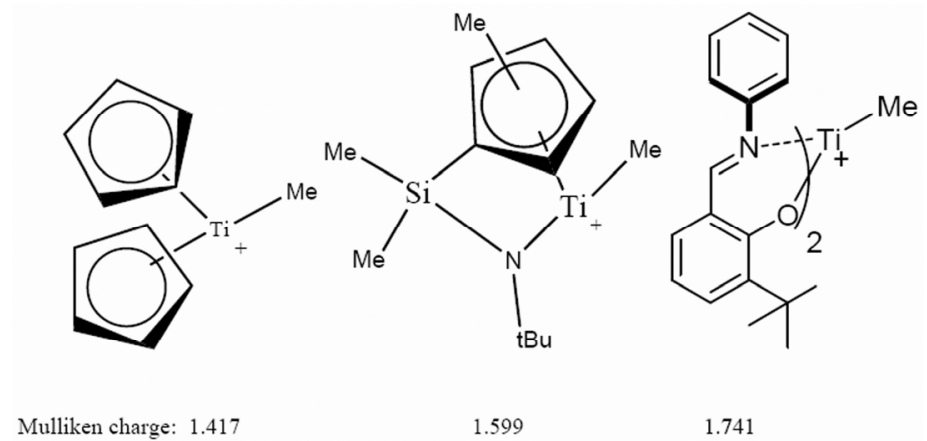

Figure 9. Mulliken charges of the central metals of cationic active Ti species [40,41].<smiles>CN=Cc1ccccc1[O-]</smiles>

2.4

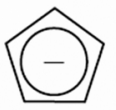

5.3

Figure 10. Energy gap between HOMO and LUMO (eV) [42].

According to the ligand-oriented catalyst design concept, Fujita and co-workers were designed transition metal complexes incorporating nonsymmetric and electronically flexible ligands as candidates for high-activity catalysts [39]. These complexes were examined as catalysts for the polymerization of ethylene with $\mathrm{MAO}$ as the cocatalyst at $25{ }^{\circ} \mathrm{C}$ under atmospheric pressure. As a result, a number of complexes were found to be highly active catalysts for the polymerization of ethylene. Polymerization results indicate that phenoxy-imine ligands can produce highly active catalysts when attached to a variety of transition metals, supporting the idea that ligands play the predominant role in polymerization catalysis and that electronically flexible ligands can engender highly active catalysts. A remarkable feature of phenoxy-imine ligated early transition metal complexes is that they possess ligands that can be readily tailored synthetically from both an electronic and steric point of view, and thus possess a wide range of possibilities in terms of catalyst design [39-41].

\section{Catalytic properties of FI Catalysts for ethylene polymerization}

One of the unique characteristics of FI catalysts, due to its flexible structure, is that the minor change in the structure of the FI catalysts leads to the major changes in activities as well as molecular weight and other characteristics of the resulting polymer. The flexibility refers to the simple Schiff base condensation of the aniline and salicylaldehyde derivatives which can produce a wide range of phenoxy-imine ligands. As depicted in Fig. 11, FI catalysts can be synthesized by treating the phenoxy-imine ligands and transition metal halids to furnish FI catalysts (Figure 11) [42]. 


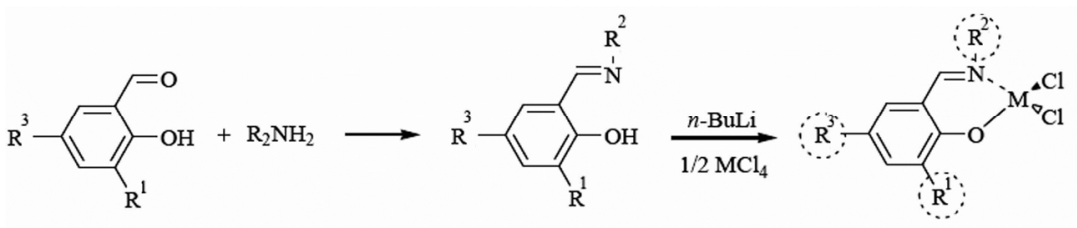

Figure 11. General procedure of FI catalysts [42].

\subsection{Influence of alkyl substitutions on the catalyst behavior}

Ethylene polymerization revealed that FI catalyst requires steric bulk ortho to the phenoxy-O in order to exhibit high ethylene polymerization activity $[42,43]$. The steric bulk is thought to afford steric protection toward the anionic phenoxy-O donors from coordination with Lewis acidic compounds such as MAO or from another molecule of the catalytically active cationic species, which are supposed to be highly electrophilic, and the inducement of effective ion separation between the cationic active species and an anionic cocatalyst, resulting in enhanced catalytic activity [44]. Moreover, Cavallo and co-workers [45] have proposed a site-inversion mechanism that can explain the unexpected syndiospecificity exhibited by the Ti-based FI complexes with $C_{2}$ symmetry. Additionally, their proposal can also explain that the steric bulk of the substituent ortho to the phenoxy-oxygen in bis(phenoxy-imine)Ti complexes plays a crucial role in determining the syndiospecificity of the polymerization $[44,45]$.

Ethylene polymerization via FI catalysts has been shown that the increase in the steric bulk of the $\mathrm{R}^{1}$ substituent resulted in the marked enhancement in both the catalytic activity and the product molecular weight [46]. The increase in the catalytic activity as a result of introducing sterically-hindered substituent at the $\mathrm{R}^{1}$ position may be attributed to the fact that the steric bulk of the $\mathrm{R}^{1}$ substituent plays an essential role in the ion separation between the cationic active species and the anionic cocatalyst. The effective ion separation will provide more space for polymerization and, in addition, enhances the degree of unsaturation associated with the catalytically active cationic species. On the other hand, the increase in the product molecular weight may be ascribed to the fact that the steric congestion exerted by the $\mathrm{R}^{1}$ substituent diminishes the rate of chain termination [46].

For instance, FI catalyst bearing a hydrogen at the $\mathrm{R}^{1}$ position $\left(\mathrm{R}^{2}=\mathrm{R}^{3}=\mathrm{H}\right)$ gave polyethylene with an $\mathrm{Mw}$ of 66,000 , displaying a moderate activity of $38 \mathrm{~kg}-\mathrm{PE} / \mathrm{mol}-\mathrm{cat} \mathrm{h}$ under these conditions. Another FI catalyst having a sterically bulkier substituent, a methyl, at the $\mathrm{R}^{1}$ position yielded much higher molecular weight polyethylene ( $M w 402,000)$ with a considerably enhanced activity of $246 \mathrm{~kg}$-PE/mol-cat h. The effects of the steric bulk of the $\mathrm{R}^{1}$ substituent were more pronounced for FI catalyst possessing a $t$-butyl group $(\mathrm{R} 1=t$-butyl) which displayed a higher activity of $3240 \mathrm{~kg}-\mathrm{PE} / \mathrm{mol}-\mathrm{cat} \mathrm{h}$ and provided polyethylene with a further enhanced molecular weight $(\mathrm{Mw}$ 1,281,000). Thus, the attachment of the methyl increased catalytic activity and product molecular weight of the produced polymer [46].

The steric bulk of the $\mathrm{R}^{2}$ substituent also has a significant influence on the catalytic performance of the complexes but differently compared with the $\mathrm{R}^{1}$ substituent [46]. A Ti-based FI catalyst 
bearing a methyl at the $\mathrm{R}^{2}$ position demonstrated an activity of $301 \mathrm{~kg}-\mathrm{PE} / \mathrm{mol}$-cat $\mathrm{h}$ and gave polyethylene with $M w$ of 355,000 . The activity and molecular weight values obtained with this catalyst are much lower than complex having hydrogen substituent $\left(\mathrm{R}^{2}=\mathrm{H}\right)$. In addition, FI catalyst with $i$-propyl at the $\mathrm{R}^{2}$ position exhibited more reduced activity (186 kg-PE/mol-cat $\mathrm{h}$ ) and furnished polyethylene with further decreased molecular weight (Mw 296,000). Therefore, it can be concluded that the increase in the steric bulk of the $\mathrm{R}^{2}$ substituent resulted in the quite deleterious effects on the catalytic activity and the product molecular weight. The decrease in the catalytic activity as a result of introducing the alkyl group into the $\mathrm{R}^{2}$ position seems reasonable and is probably attributed to the increased steric congestion in close proximity to the active site, which reduces the catalytic activity by hindering access of ethylene to the active site and/or growth of the polymer chain. However, the trend for molecular weight for the Zr-based FI catalysts is inversed, i.e., the attachment of the methyl or the $i$-propyl to the $\mathrm{R}^{2}$ position greatly enhances the product molecular weight $[47,48]$.

Eventually, the substituent at the $\mathrm{R}^{3}$ position exercised an effect on both the catalytic activity and the product molecular weight but not significantly, presumably because of the location of the $\mathrm{R}^{3}$ position being far from the polymerization center $[48,49]$.

Not only catalyst activity is affected by substitutions, but even thermal stability of the catalyst can be affected by electronic aspects of the substitutions. For instance, the introduction of an electrondonating methoxy group para to the phenoxy-O was found to increase the thermal stability of FI catalysts, making them available for polymerizations at industrially practical higher temperatures [30,39,49].

\section{Polymerization of higher $\alpha$-olefin with FI catalyst}

Catalyst systems based on bis(phenoxy-imine) complexes of $\operatorname{Ti}(\mathrm{IV}), \operatorname{Zr}(\mathrm{IV})$ and MAO are effective catalysts for polymerization of ethylene and propylene [19,33,34,38,50,51-54]. Detailed ${ }^{13} \mathrm{C}$ NMR analysis of end-groups in polypropylene prepared with several catalysts of this type showed unusual chemical and regio-effects [52,55].

Phenoxy-imine ligands in complexes contain alkyl substituents in the 2nd and the 4th positions of their phenyl rings, they produce moderately syndiospecific catalysts $[55,56]$. Detailed investigations of the $\mathrm{Ti}$ and $\mathrm{Zr}$ complexes with the same ligands showed a surprising difference in the chemistry of polymerization reactions.

Active centers of the highest stereospecificity are produced when the aryl group attached to the nitrogen atom in the phenoxyimine ligand is $\mathrm{C}_{6} \mathrm{~F}_{5}$ (Figure 3) and the phenyl group attached to the oxygen atom carries bulky t-Bu or SiMe substituents in the ortho position to the $\mathrm{C}-\mathrm{O}$ bond. The [rrrr] content in polypropylene produced with these complexes at 0-20 ${ }^{0} \mathrm{C}$ can reach $0.95-0.96$ corresponding to a very high probability of syndiotactic linking, $\sim 0.99$ [55-58]. However, a replacement of these substituents with two bromine or two iodin atoms changes the regiocontrol to primary and the stereocontrol to moderately isospecific, the $[\mathrm{mm}]$ values of polypropylene prepared at $0{ }^{\circ} \mathrm{C}$ increases from 0.17 for dialkyl-substituted complexes to 0.73 for diiodo-substituted complexes [58]. 
Bis(phenoxy-imine) complexes of $\mathrm{Ti}(\mathrm{IV})$ and $\mathrm{Zr}(\mathrm{IV})$ combined with $\mathrm{MAO}$ or with common organoaluminum compounds form effective catalysts for polymerization of ethylene, 1alkenes, and for ethylene/1-alkene copolymerization. The productivity of catalyst systems containing the $\mathrm{Ti}$ complexes and $\mathrm{MAO}$ in ethylene polymerization reactions at $25-75{ }^{\circ} \mathrm{C}$ can reach 2,000-4,000 kg/mol Ti. h [34,52,55,59-61] .

Bis(phenoxy-imine) complexes of $\mathrm{Ti}$ (IV) containing $\mathrm{C}_{6} \mathrm{~F}_{5}$ groups attached to the $\mathrm{N}$ atom in each bidentate ligand form catalyst systems with very low chain transfer rates. They copolymerize ethylene with propylene and higher 1-alkenes under living-chain conditions $(\mathrm{Mw} / \mathrm{Mn}=1.07-1.19)$ at temperatures as high as $50^{\circ} \mathrm{C}[52,55,62,63]$ and they are suitable for the synthesis of alkene block-copolymers. These catalysts were employed for the synthesis of various alkene diblock- and triblock-copolymers [48,52,55,63].

Polypropylene produced with combinations of the aldimine Ti complexes and MAO or AlR3-[Ph3C $]^{+}[\mathrm{B}(\mathrm{C} 6 \mathrm{~F} 5) 4]^{-}$as cocatalysts under moderate conditions also has a very narrow molecular weight distribution $[52,55,61,62]$. The stereospecificity of catalyst systems based on bis(phenoxy-imine) complexes depends on the type of substituents in the ligands (substituents $\mathrm{R}$ in Fig. 11). When $\mathrm{R}=\mathrm{H}$ or $\mathrm{Me}$, the catalysts produce polypropylene with a predominantly syndiotactic structure. However, complexes of the same type bearing two bromine or two iodine atoms in the 2 nd and the 4th positions of the phenyl groups produce moderately isotactic polypropylene with [mm] from $\sim 0.5$ to 0.73 , depending on reaction temperature, and the dichloro-substituted complex produces atactic polypropylene [58].

Bis(phenoxy-imine) complexes of Ti(IV) activated with ion-forming cocatalysts instead of $\mathrm{MAO}$, such as Ali-Bu3-[CPh3]+ [B(C6F5)4]- are efficient single-center catalysts for polymerization of higher 1-alkenes, 1-hexene, 1-octene, 1-decene, and 4-methyl-1-pentene. The catalysts have very high activity and produce regioand stereo-irregular polymers with very high molecular weights, $<1.4 \times 10^{6}[64]$.

The $\mathrm{Zr}$ bis(phenoxy-imine) complex was used for the synthesis of an ethylene/1-octene copolymer with a low 1-octene content, and a complex of Hf with a tridentate ligand was used for the synthesis of an ethylene/1-octene copolymer with a high 1-octene content.

The flexibility of the FI catalysts allows for the making of new polymers which are difficult or impossible to prepare using group 4 metallocene catalysts. For example, it is possible to prepare low molecular weight $\left(\mathrm{Mv} \sim 10^{3}\right)$ polyethylene or poly(ethylene-copropylene) with olefinic end groups, ultra-high molecular weight polyethylene or poly(ethylene-copropylene), high molecular weight poly(1-hexene) with atactic structures including frequent regioerrors, monodisperse poly(ethylene-co-propylene) with various propylene contents, and a number of polyolefin block copolymers [e.g., polyethylene-b-poly(ethylene-copropylene), syndiotactic polypropylene-b-poly-(ethylene-co-propylene), polyethylene-bpoly(ethylene-co-propylene)-b-syndiotactic polypropylene. These unique polymers are predictable to possess novel material properties and uses [65]. 


\section{Living polymerization with FI catalyst}

The synthesize polymers with completely defined structures is a goal. Living polymerization is known to control some elements like as degree of polymerization, chainend structures, stereochemistry, especially molecular weight and chain-end structures of polymer. Although there have been a number of transition metal catalysts which can polymerize ethylene or $\alpha$-olefins in a living fashion [66-68] there are few catalysts that are useful for both ethylene and $\alpha$-olefins. Besides, most catalysts require a low polymerization temperature, usually below room temperature, to suppress chain termination and therefore exhibit low activities and insufficient polymer molecular weights. The titanium FI catalyst bearing a perfluorophenyl group as $R$ (Figure 12) with MAO exhibited living polymerization with ethylene even at $50{ }^{\circ} \mathrm{C}$ to afford high molecular-weight polymer $\left(\mathrm{Mw}=424 \times 10^{3}\right)$ having a narrow molecular weight distribution $(\mathrm{Mw} / \mathrm{Mn}=1.13)$. This catalyst exhibits living polymerization behavior over a wide range of temperature [65].
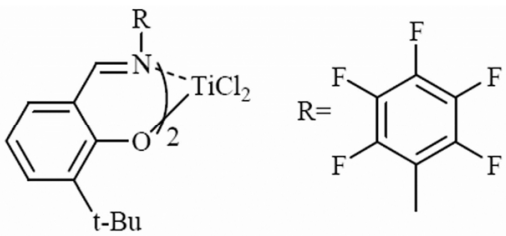

Figure 12. FI catalyst with perfluorophenyl group [65].

There is a clear difference in polymerization results depending on the fluorine substitution patterns. First of all, living polymerizations proceed only when at least one fluorine is located in the 2,6-positions of R-phenyl group (Figure 12). Second, the activity of living systems is considerably lower than that of non-living systems. Finally, the activity increases with the number of fluorine atoms in both living and non-living systems. It is reasonable that electron-withdrawing fluorines enhance the electrophilicity and consequently the reactivity of the active centers. The ortho-fluorine substituent effect represents a novel strategy for the design of a new transition metal complex for living olefin polymerization [65].

Interestingly, a titanium FI catalyst having a chlorine at the 2-position of the R-phenyl group instead of fluorine, bis[N-(3-t-butylsalicylidene)-2-chloroanilinato]titanium(IV) dichloride, also promoted ethylene polymerization at $25^{\circ} \mathrm{C}$ to produce polyethylene having a narrow molecular weight distribution ( $\mathrm{Mw} / \mathrm{Mn}=1.23$ ), implying that the interaction with $\beta$ hydrogen is potentially achieved by any substituent possessing lone-pair electrons. Propylene polymerization with the above complex (Figure 12) at room temperature also turned out to be living and produced polypropylene with a controlled molecular weight, a narrow molecular weight distribution ( $\mathrm{Mw} / \mathrm{Mn}=1.07-1.14)$, and surprisingly high syndiotacticity ( $\mathrm{rr}=87 \%, 98 \%)$ [59].

Mitani et al, introduce a Ti-FI catalyst having fluorine- and trimethylsilyl-containing ligands, which polymerizes propylene above room temperature to form highly syndiotactic 
monodisperse PPs with extremely high Tm's. The titanium complex employed in this study was bis[N-(3-trimethylsilylsalicylidene)-2,3,4,5,6-pentafluoroanilinato]Ti(IV) dichloride. Polymerization of propylene with this complex using methylalumoxane (MAO) cocatalyst under atmospheric pressure at $25{ }^{\circ} \mathrm{C}$ for $5 \mathrm{~h}$ yielded crystalline polypropylene having an extremely narrow polydispersity $(M n=47000, M w / M n=1.08)$. Interestingly, the syn-PP produced displayed an extremely high $\operatorname{Tm}\left(152^{\circ} \mathrm{C}\right)$ [69].

Kinetic studies of ethylene polymerization reactions [70] and propylene polymerization reactions [62] with FI catalysts demonstrated that all features typical for living-chain reactions are present when these reactions are carried out at $25^{\circ} \mathrm{C}$. The catalyst activity remains constant for over 1 hour in the ethylene polymerization reactions and for 3 hours in the propylene polymerization reactions and it very slowly decreases after that. The molecular weight increases with reaction time in a nearly linear manner in the same time ranges, and the molecular weight distributions of the polymers remain narrow, $\mathrm{Mw} / \mathrm{Mn}$ $=1.07-1.10$. The value of the propagation rate constant for ethylene polymerization reaction at $25^{\circ} \mathrm{C}$ was $\sim 1,400-1,900 \mathrm{M}^{-1} \cdot \mathrm{s}^{-1}$, it is comparable to the same value in metallocene catalysis [70].

The syndiospecific polymerization of propylene with this types of catalyst also exhibits kinetic features of living-chain polymerization reactions [52,55]. Both the polymer yield and the molecular weight of polypropylene produced at $0{ }^{\circ} \mathrm{C}$ increase nearly proportionally to the reaction time, and the molecular weight distribution of the polymer remains narrow $(\mathrm{Mw} / \mathrm{Mn}=1.08-1.11)$ [52]. Kinetic parameters of the propylene polymerization reactions at 0 $25{ }^{0} \mathrm{C}$ are: $\mathrm{k}_{\mathrm{p}}=0.05-0.06 \mathrm{M}^{-1} . \mathrm{s}^{-1},[\mathrm{C}] /[\mathrm{Ti}]=0.4-0.6 \%[52,71]$. However, when the same complex contains 3,5-difluoro-substituted benzene rings, chain transfer reactions occur much more readily and the polymer has the typical molecular weight distribution characteristics of a material synthesized with a single-center catalyst, $\mathrm{Mw} / \mathrm{Mn} \sim 2.5$ [55].

Polymerization reactions with $\mathrm{Ti}$ diamide-based catalysts: Low-temperature propylene polymerization reactions with a Ti diamide complex LTiMe2 activated with MMAO or with silica- and alumina-supported MMAO give an interesting example of long-term living-chain reactions. These catalysts are very stable kinetically at $0{ }^{\circ} \mathrm{C}$ and the $\mathrm{Mn}$ value of the produced polymers increases with time in a linear manner for over 30 minutes resulting in the formation of atactic polymers of a very high molecular weight, with $\mathrm{Mn} \sim 1.5 \times 10^{6}$. The $\mathrm{k}_{\mathrm{p}}$ value for the homogeneous catalyst system is $\sim 5 \mathrm{M}^{-1} \cdot \mathrm{s}^{-1}$ at $0{ }^{0} \mathrm{C}$ and when MMAO is supported on silica (this step increases the acidity of $\mathrm{Al}$ atoms in MMAO), the $\mathrm{k}_{\mathrm{p}}$ value increases to $\sim 20 \mathrm{M}^{-1} \cdot \mathrm{s}^{-1}[72,73]$.

\section{Modification of the FI catalysts}

Fujita group at Mitsui Chemicals discovered the fluorinated Ti-FI catalysts that can promote unprecedented living ethylene and propylene polymerization, resulting in the formation of functionalized polymers and block copolymers from ethylene, propylene, and higher $\alpha$ olefins [59]. Coates [74] and Sakuma [75] reported that fluorinated Ti-FI catalysts are capable of mediating the highly controlled, thermally robust living polymerization of 
ethylene and propylene. Electronic attractive interaction between a fluorinated phenoxyimine ligand and a growing polymer chain has significant effects on the catalytic properties of Ti-FI catalysts [59,74,75]. Additionally, the presence of electron withdrawing fluoro substituents on aniline is considered to be highly beneficial for increasing the catalyst activity. Ishii and coworkers described that introduction of electron-withdrawing $\mathrm{F}$ atoms on the ligand structure results in an increase in metal-carbon reactivity leading to reduced activation energy for ethylene insertion [76].

Although the catalytic behavior of ethylene and propylene polymerization, as well as ethylene-propylene copolymerization, using fluorinated Ti-FI complexes are extensively described in literature [77-79], but less attention has been paid to the fluorinated Zr-FI complexes. Recently, Zohuri and coworkers have reported the catalytic properties of a fluorinated Zr-FI catalyst in ethylene polymerization (Figure 13) [3].
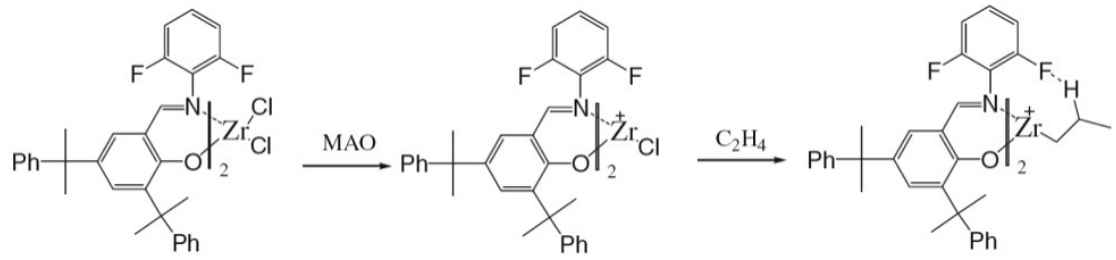

Figure 13. Structure of the new Zr-FI catalyst and the electronically interaction between H-b and orthoF-atom-substituted phenyl ring on the $\mathrm{N}[3]$.

The synthesized catalyst could produce polyethylene with high molecular weight $\left(\mathrm{M}_{\mathrm{v}}=1.39\right.$ $\times 10^{6}$ ) which is surprisingly higher in comparison with the similar non-fluorinated FI catalysts $[33,42]$ indicating the dramatic electronic effect of ortho-F substitution on the polymerization mechanism [3] (Fig. 13). The $\mathrm{M}_{\mathrm{v}}$ values of $36 \times 10^{4}, 10.4 \times 10^{4}$, and $1.84 \times 10^{4}$ have been reported already for the polyethylene obtained using the non-fluorinated bis[N(3-t-butyl-5-methoxy salicylidene) anilinato] zirconium (IV) dichloride, bis[N-(3-cumyl-5methoxy salicylidene) cyclohexy laminato] zirconium (IV) dichloride and bis[(3-cumyl-5methyl salicylidene) anilinato] zirconium (IV) dichloride, respectively [33,74]. It has been proposed that attractive interaction between the ortho- $\mathrm{F}$ and the $\beta-\mathrm{H}$ on a growing polymer chain, which is expected to effectively curtail $\beta-\mathrm{H}$ transfer to the central metal and incoming monomer, is responsible for the unprecedented behavior [42]. Furthermore, it has been shown that ortho-F-substituted phenyl ring on the $\mathrm{N}$ electronically plays a key role in the suppression of chain transfer reactions resulted in increasing the molecular weight and moderation of the catalyst activity [3].

Additionally, a highly active Zr-based FI catalyst of bis[N-(3,5dicumylsalicylidene)cyclohexyl-aminato]zirconium(IV) dichloride has been synthesized and used for polymerization of ethylene by Zohuri et al [80]. The synthesized catalyst by changing the phenyl group on the imine nitrogen of FI catalyst (Fig. 11, R2) to a cyclohexyl group exhibited enhanced activity, may be due to the electron-donating effects of an aliphatic group at the $\mathrm{R}_{2}$ position. The prepared FI catalyst displayed a very high activity of 
about $3.2 \times 10^{6} \mathrm{~g} \mathrm{PE} / \mathrm{mmol} \mathrm{Zr}$. $\mathrm{h}$ in ethylene polymerization at the monomer pressure of 3 bars. Despite such high activity, this catalyst showed a short lifetime [80].

Some complexes with ligands based on naphthalene carbaldehydes having a hydroxy group in the ortho position with respect to the aldehyde group were described [81,82], but no data on their catalytic activity were given. Ahmadjo and coworkers [53] used 2hydroxynaphtaldehyde instead of salicylaldehyde for the preparation of naphthoxy-imines as ligands and three FI-like Zr-based catalysts, Bis[1-[(phenylimino)methyl]-2naphtholato]zirconium(IV) dichloride (1), Bis[1-[(mesitylimino)methyl]-2-naphtholato] zirconium(IV) dichloride (2) and Bis[1-[(2,6-diisopropylphenyl)imino] methyl-2naphtholato]zirconium(IV) dichloride (3) were prepared by changing the ligand from salicylaldehyde imine ligand, to 2-hydroxynaphthalene-1-carbaldehyde imine ligand and used for polymerization of ethylene (Figure 14) [53]. It has been reported that introducing the sterically bulky isopropyl groups enhances molecular weight of the resulting polymer through destabilization of $\beta$-agostic interaction due to the steric repulsion between $\beta$ hydrogen of the growing polymer and isopropyl leading to decrease the $\beta-\mathrm{H}$ elimination [34].
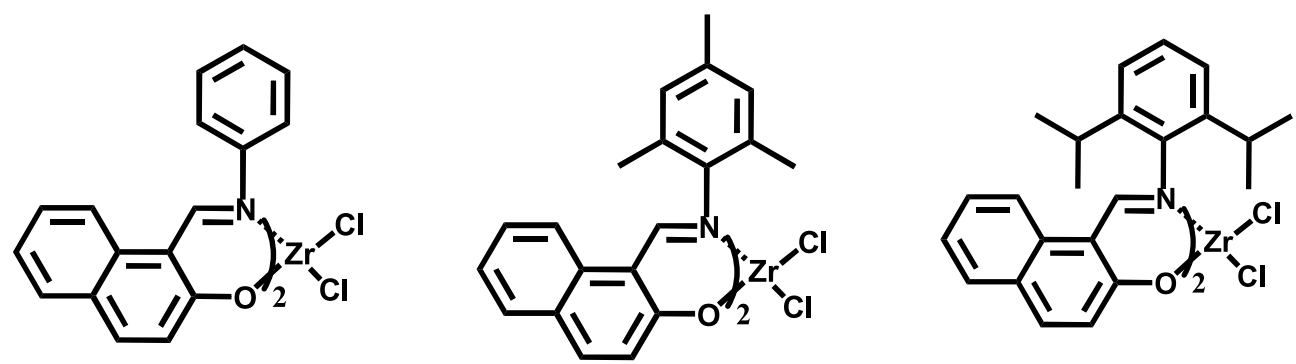

Figure 14. Structure of the new FI catalysts reported by Ahmadjo et al [53].

The transition state for $\beta$-hydride elimination requires the overlapping of a $\sigma \mathrm{C}-\mathrm{H}$ orbital with an empty $d$ orbital of the metal, and the two carbon adjacent to the metal and $\beta$ hydrogen must be on the same plane containing the metal between the two phenoxy-imine kelates. Therefore, the energy of the conformation needed for $\beta$-hydride elimination increases with increase of steric hindrance around the metal [83,84]. In the catalyst containing bulky isopropyl group phenyl ring on the $\mathrm{N}$ (Figure 14), it seems that $\beta$-carbon of polymer chain is not easily accommodated in the plane because of the steric interaction between naphthoxy-imine ligands of the catalyst and $\beta-\mathrm{H}$ of the growing polymer chain (Figure 15). It can be concluded that the sterically bulky substituents on the aniline ring of the naphthoxy-imine ligands cause a strong suppression of the both $\beta$-hydride elimination and $\beta$-hydride transfer to monomer leading to increase the molecular weight of the resulted polymer [53].

Moreover, Damavandi and coworkers have reported the synthesis of novel FI Zr-type catalysts for ethylene polymerization [85]. Figure 16 depicted the structure of the catalysts. 
Steric repulsion

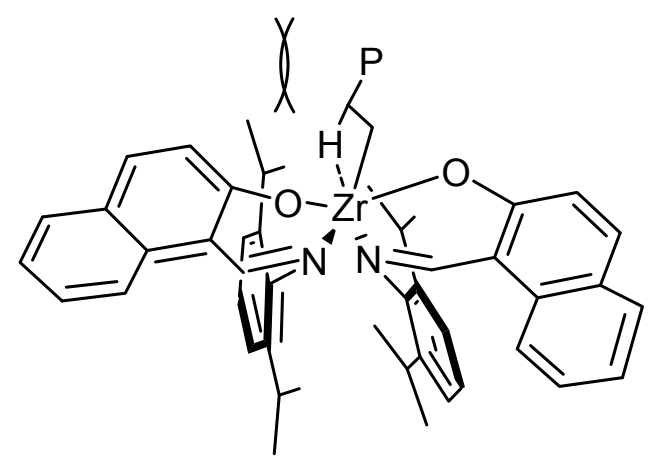

Figure 15. $\beta$-agostic interaction: steric repulsion between $\beta$-hydrogen of the growing polymer chain and isopropyl alkyl substitutions phenyl ring on the $\mathrm{N}$ [53].
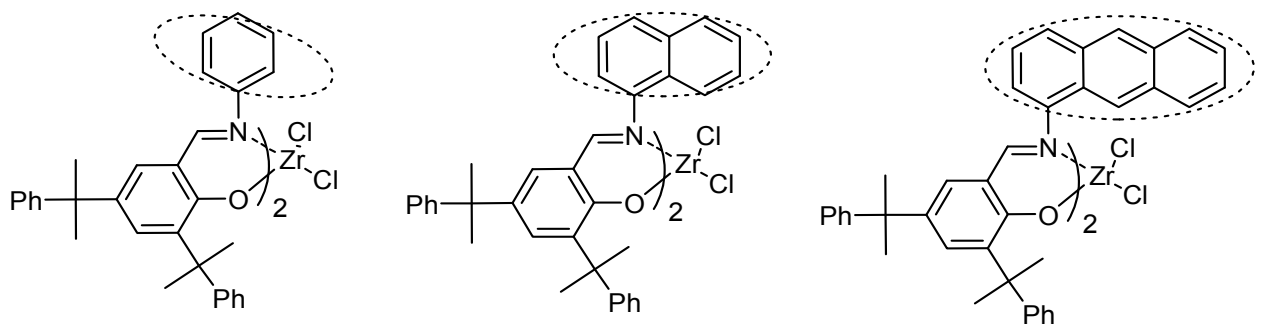

Figure 16. Structure of the FI Zr-type catalysts [85].

Plurality of the fused aromatic rings on the $\mathrm{N}$ atom of the imine in the catalyst structure affected the polymerization activity and molecular weight of the resulting polymer as well. It has been reported that changing of ligand from FI-type single aryl substituted on the $\mathrm{N}$ atom of imine to further aromatic fused rings, enhances the steric hindrance of the catalyst which resulted in diminishing the catalyst activity in comparison with FI catalysts including single aryl substituted on the N. However, this replacement could increase the molecular weight of the polymer obtained. It is presumable that rigidity of the catalyst structure, sterically causes low $\beta$-hydride transfer through destabilization of $\beta$-agostic interaction. The $\mathrm{M}_{\mathrm{v}}$ values of the obtained polymer using the catalyst containing naphtholato group were higher than the obtained polymer using the catalyst containing anilinato group (Fig. 15). The increase in $\mathrm{M}_{v}$ values is referred to the steric repulsion between a $\beta$-hydrogen of growing polymer and aromatic fused rings on the imine-N which could diminish $\beta$-hydride elimination through destabilization of $\beta$-agostic interaction $[53,85]$.

Furthermore, Damavandi et al. showed that polydispersity can remarkably increase with time which reveals that the system starts to deviate from pure living behavior [85]. Although a linear dependence between the polymerization time and the molecular weight was observed indicating for living behavior, but the polydispersity was broadened with the 
time (Figure 17). The reason can be that either the catalyst is not truly living over the full polymerization time or that the single-site system turns into a multi-site system due to heterogenization of the system. This phenomenon could be comparable with selfimmobilization of single site catalysts that has been a subject of interest [86]. Similar result has been reported already by Ivanchev et. al [87]. The capture and blocking of active sites by the grown polymer after a certain polymerization time have been suggested.

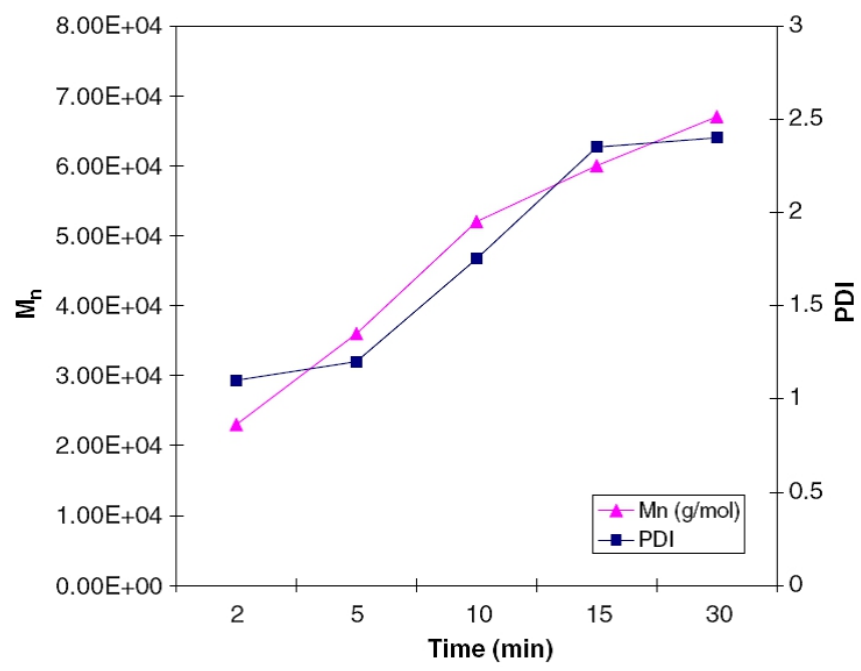

Figure 17. PDI and Mn versus time [85].

Also, Sandaroos and coworkers reported the synthesis and structure of novel Ti complex having a pair of chelating aminotropone [O-N] ligand [88]. Experimental as well as theoretical studies show that the active species derived from bis(aminotropone) Ti catalyst normally possess higher electrophilicity nature compared with those produced using bis(phenoxyimine) Ti complexes (Ti-FI catalysts) (Figure 18) [88].

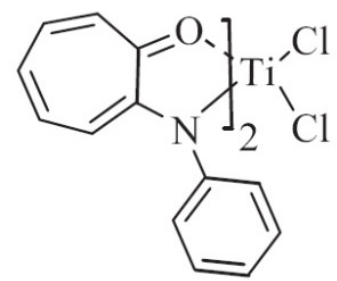

Figure 18. Structure of bis(aminotropone) Ti catalyst [88].

Ahmadjo et al. [53] Studied ethylene polymerization using FI catalysts in the presence of different amount of hydrogen. They reported that the polymerization activity can be increased with increasing the hydrogen concentration due to the fast hydrogenation of sterically more hindered and less reactive intermediates such as those resulting from 2,1insertions (Figure 19) [53]. 


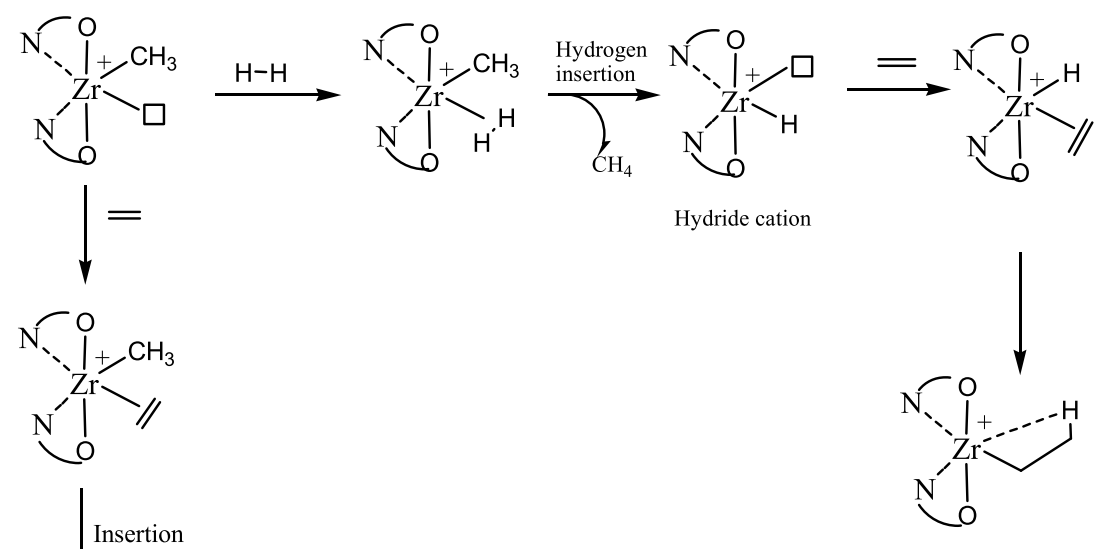

Olefin hydride complex intermediate
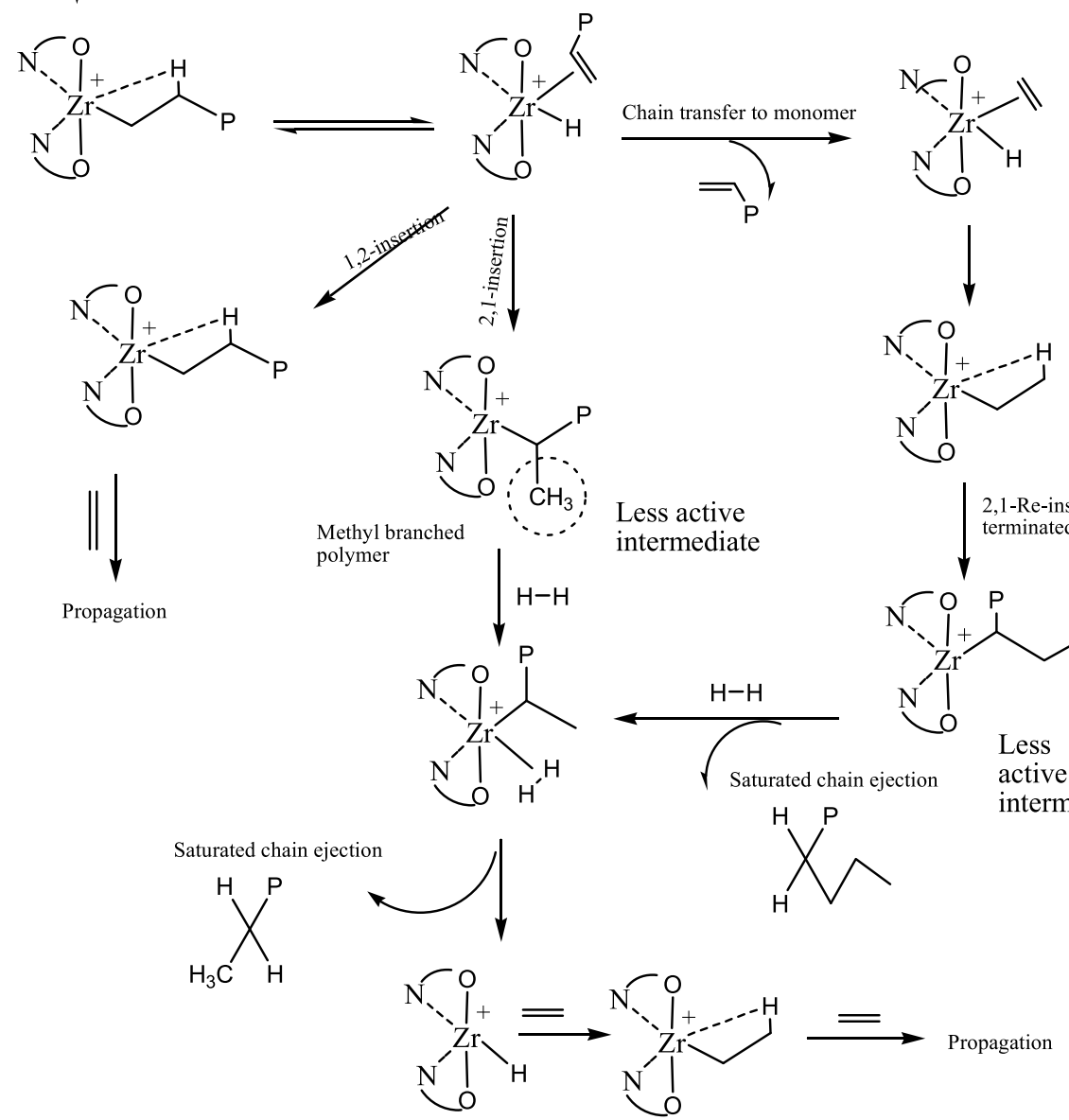

Less active

2,1-Re-insertion of terminated chain

Propagation
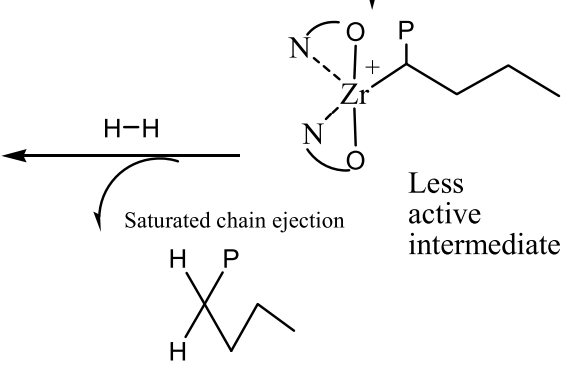

Propagation

Figure 19. Proposed mechanisms for reactivation of catalyst active centers by hydrogen [53]. 
Isomerization is possible when the polymer chain at the $\mathrm{Zr}$ center undergoes $\beta$-hydride elimination forming an intermediate of olefin hydride complex and the olefin reinserts in a 2,1-manner into the $\mathrm{Zr}$-hydride bond before insertion of the next monomer takes place. Consequently, methyl branches are formed (Figure 19). The new $\mathrm{Zr}-\mathrm{C}$ bond is expected to be more hindered and less reactive for further monomer insertion which can be reactivated by hydrogen. As it is shown in Figure 19, in the presence of hydrogen, a dihydrogen complex is formed in the first step. This intermediate can subsequently form a hydride cation and a saturated alkyl chain, which is ejected from the active site. A new ethylene monomer can be inserted into the hydride cation structure and a new polymer chain starts to grow [53].

Additionally, 2,1-reinsertion of short olefin branches, terminated by $\beta-\mathrm{H}$ elimination which are still capable to be coordinated to the active centers, is probable. As it is shown in Figure 19 , in the presence of hydrogen, the resulting sterically more hindered and less reactive intermediate undergoes fast hydrogenation to form hydrid cation which is susceptible to start new ethylene polymerization. However, it has been suggested that the catalyst structure limits the hydrogen role during the polymerization specifically in the latest ligandoriented catalysts [53].

\section{Immobilizing polymerization catalysts}

The cocatalysts for bis(phenoxy-imine) $\mathrm{Zr}$ and $\mathrm{Ti}$ complexes are generally MAO (methylaluminoxane), $i$-Bus $\mathrm{Al} / \mathrm{Ph}_{3} \mathrm{CB}\left(\mathrm{C}_{6} \mathrm{~F}_{5}\right)_{4}[64,79,89]$, or $\mathrm{MgCl}_{2}$-based activators [73]. There has been few report on common alkylaluminums alone as cocatalyst in the catalytic system of bis(phenoxy-imine) $\mathrm{Zr}$ and $\mathrm{Ti}$ complexes, they used some alkylaluminums, such as triethylaluminum $\left(\mathrm{Et}_{3} \mathrm{Al}\right)$, trihexylaluminum $\left(\mathrm{He}_{3} \mathrm{Al}\right)$, or trimethylaluminum $\left(\mathrm{Me}_{3} \mathrm{Al}\right)$, could activate bis(phenoxy-imine) $\mathrm{Zr}$ and Ti complexes for ethylene polymerization without MAO or $\mathrm{Ph}_{3} \mathrm{CB}\left(\mathrm{C}_{6} \mathrm{~F}_{5}\right)_{6}$, It is found that only the alkylaluminum with three linear alkyls can activate catalyst. However, no polymer was found using $i$-Bus $\mathrm{Al}$ or $\mathrm{Et}_{2} \mathrm{AlCl}$ as cocatalyst for complex. The molecular weights of the polyethylenes produced by FI catalyst with $\mathrm{Et}_{3} \mathrm{Al}, \mathrm{He}_{3} \mathrm{Al}$, or $\mathrm{Me}_{3} \mathrm{Al}$ are much higher than those produced with MAO. Also the polydispersities $(\mathrm{Mw} / \mathrm{Mn})$ of polyethylenes produced by FI catalyst with trialkylaluminums are higher than with MAO [54].

Up to now, several highly active transition metal complexes including metallocenes with $\mathrm{MgCl}_{2}$-based activator catalyst systems, often introduced as $\mathrm{MgCl}_{2}$-supported catalyst systems, have been reported $[90,91]$. These catalyst systems normally give polymers with broad molecular weight distributions.

$\mathrm{MgCl}_{2}$ may work as an activator for the bis(phenoxy-imine)Ti complexes since these complexes possess $\mathrm{O}$ and $\mathrm{N}$ heteroatoms in the ligands, which are capable of electronically interacting with $\mathrm{MgCl}_{2}$. Thus, researcher decided to investigate $\mathrm{MgCl}_{2}$ as an activator for the bis(phenoxy-imine)Ti complexes in the hope of developing high performance catalysts based on these complexes [73,92].

At first dealcoholysis of a $\mathrm{MgCl}_{2} /$ alcohol adduct with $i$-Bus $\mathrm{Al}$ since this method produces highly porous small $\mathrm{MgCl}_{2}$ particles, which should be suitable as an activator. Ethylene 
polymerization with complexes $\quad \operatorname{Bis}[N-(3-t$-butylsalicylidene)anilinato]titanium(IV) dichloride (1), Bis[N-(3-t-butylsalicylidene)cyclohexylaminato]titanium(IV) dichloride (2), Bis[N-(3-phenylsalicylidene)anilinato]titanium(IV) dichloride (3) were conducted under ethylene $\left(0.9 \mathrm{MPa}\right.$ pressure) at $50{ }^{\circ} \mathrm{C}$ for $30 \mathrm{~min}$ using the above mentioned $\mathrm{MgCl}_{2} / \mathrm{i}-$ $\mathrm{Bu} m \mathrm{Al}(\mathrm{OR})_{n}$ as an activator [92].

$i$-Butylaluminum 2-ethyl-1-hexoxide, $i$ - $\mathrm{Bu} m \mathrm{Al}(\mathrm{OR})_{n}$, such as $i$ - $\mathrm{Bu}_{2} \mathrm{Al}$ (2-ethyl-1-hexoxide), are expected to work as in situ alkylating reagents for the Ti complexes as well as scavengers in a polymerization sysytem, and $\mathrm{MgCl}_{2}$ may function as a Lewis acid to generate a cationic active species from an alkylated complex [93].

The complexes with $\mathrm{MgCl}_{2} / i-\mathrm{Bu} m \mathrm{Al}(\mathrm{OR})_{n}$ activator systems displayed high activities in the range of $20.8-36.3 \mathrm{~kg}-\mathrm{PE} / \mathrm{mmol} \mathrm{cat} \cdot \mathrm{h}$, with a steady uptake of ethylene over the $30 \mathrm{~min}$ duration of the run.

It is of great significance that the activities obtained using $\mathrm{MgCl}_{2} / i-\mathrm{Bu}_{m} \mathrm{Al}(\mathrm{OR})_{n}$ as the activator are comparable to those seen with the MAO activator system. Notably, the activities obtained with complexes $/ \mathrm{MgCl}_{2} / i-\mathrm{Bu} m \mathrm{Al}(\mathrm{OR})_{n}$ are comparable to or exceed that found for the $\mathrm{Cp}_{2} \mathrm{TiCl}_{2} / \mathrm{MAO}$ catalyst system under the same conditions. Alternatively, complexes 1-3 combined with $i-\mathrm{Bu} m \mathrm{Al}(\mathrm{OR}) n$ or $i-\mathrm{Bu} 3 \mathrm{Al}$ exhibited practically no activities under identical polymerization conditions. These results demonstrated that $\mathrm{MgCl}_{2} / \mathrm{i}-$ $\mathrm{Bu} m \mathrm{Al}(\mathrm{OR})_{n}$ is an effective activator for bis(phenoxy-imine)Ti complexes, and $\mathrm{MgCl}_{2}$ is a pivotal component of the activator. The high performance exhibited by $\mathrm{MgCl}_{2} / i-\mathrm{Bu}_{m} \mathrm{Al}(\mathrm{OR})_{n}$ as the activator towards the bis(phenoxy-imine)Ti complexes 1-3 may be related to the fact that the bis(phenoxy-imine) complexes possess $\mathrm{O}$ and $\mathrm{N}$ heteroatoms in the ligand, which are capable of electronically interacting with $\mathrm{MgCl}_{2}$.Remarkably, the molecular weight distribution $(\mathrm{Mw} / \mathrm{Mn})$ values of the polyethylenes arising from complexes $1-3 / \mathrm{MgCl}_{2} / \mathrm{i}$ $\mathrm{Bu} m \mathrm{Al}(\mathrm{OR})_{n}$ systems lie in the range of 2.40-2.67 (MAO activation; 2.07-2.74), suggesting that the polymers are produced by single active species [92].

Moreover, Bis(phenoxy-imine) $\mathrm{V}$ complex in association with $\mathrm{MgCl}_{2} / \mathrm{RmAl}(\mathrm{OR})_{\mathrm{n}}$ demonstrate high activities at elevated temperatures $\left(75{ }^{\circ} \mathrm{C}, 65.1 \mathrm{~kg}-\mathrm{PE} /(\mathrm{mmol}-\mathrm{cat} \mathrm{h})\right.$, atmospheric ethylene pressure) and a thermally robust single-site V-based olefin polymerization catalysts. All of the $\mathrm{V}$ compounds with $\mathrm{MgCl}_{2} / \mathrm{Etm}_{\mathrm{m}} \mathrm{Al}(\mathrm{OR})_{\mathrm{n}}$ provided very high molecular weight PEs $(\mathrm{Mv}>5,000,000)$ for which we are unable to determine the molecular weights and molecular weight distributions using GPC analyses. All of the polyethylenes formed from the $\mathrm{MgCl}_{2} / \mathrm{RmAl}(\mathrm{OR})_{\mathrm{n}}$ systems display good polymer morphology, indicating that complexes are heterogenized on the surface of the $\mathrm{MgCl}_{2} / \mathrm{RmAl}(\mathrm{OR})_{\mathrm{n}}$. These results suggest that $\mathrm{MgCl}_{2} / \mathrm{RmAl}_{\mathrm{m}}(\mathrm{OR})_{\mathrm{n}}$ not only works as an excellent cocatalyst, but is also a good support for phenoxy-imine ligated $\mathrm{V}$ complexes [73].

$\mathrm{Xu}$ et al reported Bis(phenoxy-imine) zirconium catalyst, bis-[N-(3-tertbutylsalicylidence) cyclohexylaminato] zirconium(IV) dichloride, that directly impregnated onto MAO modified spherical $\mathrm{MgCl}_{2}$ support . The resultant solid catalyst was proved to be very active in ethylene polymerization, leading to the formation of spherical polymer particles with high bulk density. The activities of supported catalysts and the bulk density of the resultant 
PEs are strongly dependent on dealcoholization temperature, while dealcoholization temperature also influences the molecular weight and molecular weight distribution of the resultant polymers. When the support was thermally pretreated at lower temperature, the resultant solid catalysts, were inactive for ethylene polymerization. On the contrary, when the support was pretreated at higher temperature, the corresponding solid catalysts were all active for ethylene polymerization [94].

Ethylene polymerization by titanium complex having two phenoxy-imine with different supports and solvents has been investigated by Srijumnong et al [95]. The catalytic activity depended on supports used, and especially on the types of solvent medium. For the supported system, catalytic activities decreased in the following order: $\mathrm{TiO}_{2}>\mathrm{TiO}_{2}-\mathrm{SiO}_{2}>$ $\mathrm{SiO}_{2}$. This can be attributed to the strong interaction of the $\mathrm{TiO} 2$ with dried MMAO (dMMAO) and the larger amount of dMMAO present on the $\mathrm{TiO}_{2}$ than other supports.

Zhang et al. reported self-immobilized titanium and zirconium complexes with allyloxy substituted phenoxy-imine ligands as well as their catalytic performance for ethylene polymerization. The results of ethylene polymerization showed that the self-immobilized titanium (IV) and zirconium (IV) catalysts kept high activity for ethylene polymerization. SEM showed the immobilization effect could greatly improve the morphology of polymer particles to afford micron-granula polyolefin as supported catalysts. Polymer produced by self-immobilized catalysts had broader molecular weight distribution (3.5-19.2), while polymer produced by titanium and zirconium complexes free from allyloxy groups had very narrow molecular weight distribution $(<3.0)$ in most case [96].

\section{Author details}

\section{S. Damavandi}

Department of Chemistry, Sarvestan Branch, Islamiz Azad University, Iran

S. Ahmadjo

Department of Catalyst, Iran Polymer and Petrochemical Institute, Tehran, Iran

R. Sandaroos

Department of Chemistry, Faculty of Science, Birjand University, Birjand, Iran

G.H. Zohuri*

Department of Chemistry, Ferdowsi University of Mashhad, Mashhad, Iran

\section{References}

[1] Brinzingger HH, Fisher, D, Mulhaupt R, Rieger R, Waymouth RM (1995) Stereospecific Olefin Polymerization with Chiral Metallocene Catalysts. Angew. Chem. Int. Eng. 34: 1143-1170.

\footnotetext{
${ }^{*}$ Corresponding Author
} 
[2] Kaminsky W, (1999) Metalorganic Catalysts for Synthesis and Polymerization. SpringerVerlag, Heidelberg.

[3] Zohuri GH, Damavandi S, Sandaroos R, Ahmadjo S (2011) Ethylene Polymerization Using Fluorinated FI Zr-Based Catalyst. Polym. Bull. 66: 1051-1062.

[4] Kaminsky W, (2005) in Handbook of Polymer Synthesis, $2^{\text {nd }}$ ed. Kricheldorf H, Nuyken O, Swift G, Eds. Marcel Dekker, New York, Pp 1-73.

[5] Kuran W, (2001) Principles of Coordination Polymerization, Wiley, New York.

[6] Moor EP, (2003) Polypropylene Handbook, Hanser; Munich, Germany.

[7] Resconi L, Cavallo L, Fait A, Piemontesi F, (2000) Selectivity in Propene Polymerization with Metallocene Catalysts. Chem. Rev. 100: 1253-1345.

[8] Wang B (2006) Ansa-Metallocene Polymerization Catalysts: Effects of the Bridges on the Catalytic Activities. Coord. Chem. Rev. 250: 242-258.

[9] Irwin LJ, Miller SA (2007) Catalyst System for High Activity and Stereoselectivity in the Homopolymerization and Copolymerization of Olefins. U.S. Patent 7214749.

[10] Yoshida Y, Matsui S, Fujita T (2010) FI Catalysts: Unique Olefin Polymerization Catalysis for Formation of Value-added Olefin-based Materials. Journal of the Japan Petroleum Institute, 53: (3), 111-129.

[11] Kaminsky W (2004) The Discovery of Metallocene Catalysts and Their Present State of the Art. J Polym. Sci. Part A. 42: 3911-3921.

[12] Gibson VC, Spitzmesser SK (2003) Advances in Non-Metallocene Olefin Polymerization Ccatalysis. Chem. Rev. 103: 283-315.

[13] Britovsek GJP, Gibson VC, Wass DF (1999) The Search for New-Generation Olefin Polymerization Catalysts: Life Beyond Metallocenes. Angew. Chem. Int. Ed. 38: 428-447.

[14] Baumann R, Davis WM, Schrock RR (1997) Synthesis of Titanium and Zirconium Complexes that Contain the Tridentate Diamido Ligand, [((t-Bu-d6) N-o- $\left.{ }_{6} \mathrm{H}_{4}\right)_{2} \mathrm{O}_{2}-$ $\left([\mathrm{NON}]_{2}-\right)$ and the Living Polymerization of 1-Hexene by Activated [NON]ZrMez. J. Am. Chem. Soc. 119: 3830-3831.

[15] Nomura K, Sagara A, Imanishi Y (2002) Olefin Polymerization and Ring-Opening Metathesis Polymerization of Norbornene by (Arylimido)(Aryloxo)Vanadium(V) Complexes of the Type $\mathrm{VX}_{2}(\mathrm{NAr})(\mathrm{OAr} \$)$. Remarkable Effect of Aluminum Cocatalyst for the Coordination and Insertion and Ring-Opening Metathesis Polymerization. Macromolecules 35: 1583-1590.

[16] Johnson LK, Killian CM, Brookhart M (1995) New Pd(II)- and Ni(II)-Based Catalysts for Polymerization of Ethylene and $\alpha$-Olefins. J. Am. Chem. Soc. 117:6414-6415.

[17] Quijada R, Rojas R, Bazan G, Komon ZJA, Mauler RS, Galland GB (2001) Synthesis of Branched Polyethylene from Ethylene by Tandem Action of Iron and Zirconium Single Site Catalysts. Macromolecules 34: 2411-2417.

[18] Azoulay JD, Bazan GC, Galland GB (2010) Microstructural Characterization of Poly(1hexene) Obtained Using a Nickel R-Keto- $\beta$-diimine Initiator. Macromolecules 43:27942800 .

[19] Terao H, Ishii S, Mitani M, Tanaka H, Fujita T (2008) Ethylene/Polar Monomer Copolymerization Behavior of Bis(phenoxy-imine)Ti Complexes: Formation of Polar Monomer Copolymers. J. Am. Chem. Soc. 130: 17636-17637. 
[20] Suzuki Y, Terao H, Fujita T (2003) Recent Advances in Phenoxy-Based Catalysts for Olefin Polymerization. Bull. Chem. Soc. Jpn. 76: 1493-1517.

[21] Furuyama R, Saito J, Ishii SI, Mitani M, Tohi Y, Makio H, Matsukawa N, Tanaka H, Fujita T (2003) Ethylene and Propylene Polymerization Behavior of a Series of Bis(Phenoxy-imine)Titanium Complexes. J. Mol. Cat. A. 200: 31-42.

[22] Mecking S, Johnson LK, Wang L, Brookhart M (1998) Mechanistic Studies of the Palladium-Catalyzed Copolymerization of Ethylene and $\alpha$-Olefins with Methyl acrylate. Journal of the American Chemical Society, 120(5): 888-899.

[23] Liu W, Malinoski JM, Brookhart M (2002) Ethylene Polymerization and Ethylene/Methyl 10-undecenoate Copolymerization Using nickel(II) and Palladium(II) Complexes Derived from a Bulky P,O Chelating Ligand. Organometallics, 21(14): 28362838.

[24] Sun J, Shan Y, Xu Y, Cui Y, Schumann H, Hummert M (2004) Novel CyclohexylSubstituted salicylaldiminato-Nickel(II) Complex as a Catalyst for Ethylene Homopolymerization and Copolymerization. J. Polym. Sci. Part A, Polym. Chem. 42 (23): 6071-6080.

[25] Matsugi T, Matsui S, Kojoh S, Takagi Y, Inoue Y, Nakano T, Fujita T, Kashiwa N (2002) New Titanium Complexes Bearing Two Indolide-Imine Chelate Ligands for the Polymerization of Ethylene. Macromolecules, 35: 4880-4887.

[26] Yoshida, Y, Mohri J, Ishii S, Mitani M, Saito J, Matsui S, Makio H, Nakano T, Tanaka H, Onda M, Yamamoto Y, Mizuno A, Fujita T (2004) Living Copolymerization of Ethylene with Norbornene Catalyzed by Bis(Pyrrolide-Imine) Titanium Complexes with MAO. J. Am. Chem. Soc. 126: 12023-12032.

[27] Suzuki Y, Inoue Y, Tanaka H, Fujita T (2004) Phenoxyether Ligated Ti Complexes for the Polymerization of Ethylene. Macromol. Rapid Commun. 25: 493-497.

[28] Suzuki, Y, Tanaka H, Oshiki T, Takai K, Fujita T (2006) Titanium and Zirconium Complexes with Non-Salicylaldimine-Type Imine-Phenoxy Chelate Ligands: Syntheses, Structures, and Ethylene-Polymerization Behavior. Chem. Asian J. 1: 878-887.

[29] Matsugi T, Fujita T, (2008) High-Performance Olefin Polymerization Catalysts Discovered on the Basis of a New Catalyst Design Concept. Chem. Soc. Rev. 37: 12641277.

[30] Fujita T, Tohi Y, Mitani M, Matsui S, Saito J, Nitabaru M, Sugi K, Makio H, Tsutsui T (1998) Olefin Polymerization Catalysts, Transition Metal Compounds, Processes for Olefin Polymerization, and Alpha-Olefin/Conjugated Diene Copolymers. EP Patent 0874005 .

[31] Matsugi T, Fujita T (2008) High Performance Olefin Polymerization Catalysts Discovered on the Basis of a New Catalyst Design Concept, Chem. Soc. Rev. 37: 12661277.

[32] Tohi Y, Nakano T, Makio H, Matsui S, Fujita T, Yamaguchi T (2004) Polyethylenes Having Well-Defined Bimodal Molecular Weight Distributions Formed with Bis(phenoxy-imine) Zr Complexes, Macromol. Chem. Phys. 205: 1179-1183.

[33] Matsui S, Mitani M, Saito J, Tohi Y, Makio H, Matsukawa N, Takagi Y, Tsuru K, Nitabaru M, Nakano T, Tanaka H, Kashiwa N, Fujita T (2001) J. Am. Chem. Soc. A 
Family of Zirconium Complexes Having Two Phenoxy-Imine Chelate Ligands for Olefin Polymerization, 123: 6847-6856.

[34] Tohi Y, Makio H, Matsui S, Onda M, Fujita T (2003) Polyethylenes with Uni-, Bi-, and Trimodal Molecular Weight Distributions Produced with a Single Bis(phenoxy-imine)zirconium Complex. Macromole. 36: 523-525.

[35] Strauch J, Warren TH, Erker G, Fröhlich R, Saarenketo P (2000) Formation and Structural Properties of Salicylaldiminato Complexes of Zirconium and Titanium. Inorg. Chim. Acta. 300-302: 810-821.

[36] Johnson, AL, Davidson MG, Lunn MD, Mahon MF (2006) Synthesis, Isolation and Structural Investigation of Schiff-Base Alkoxytitanium Complexes: Steric Limitations of Ligand Coordination. Eur. J. Inorg. Chem. 15: 3088-3098.

[37] Pärssinen A, Luhtanen T, Klinga M, Pakkanen T, Leskelä M, Repo T (2007) Alkylphenyl-Substituted Bis(salicylaldiminato) Titanium Catalysts in Ethene Polymerization. Organometallics, 26: 3690-3698.

[38] Mitani M, Saito J, Ishii S, Nakayama Y, Makio H, Matsukawa N, Matsui S, Mohri J, Furuyama R, Terao H, Bando H, Tanaka H, Fujita T (2004) FI Catalysts: New Olefin Polymerization Catalysts for the Creation of Value-Added Polymers. Chem. Rec. 4: 137158.

[39] Makio H, Fujita T (2009) Development and Application of FI Catalysts for Olefin Polymerization: Unique Catalysis and Distinctive Polymer Formation. Acc. Chem. Res. 42: (10) 1532-1544.

[40] Chen E YX, Marks T J (2000) Cocatalysts for Metal-Catalyzed Olefin Polymerization: Activators, Activation Processes, and Structure-Activity Relationships. Chem. Rev. 100: 1391-1434.

[41] Matsui S, Mitani M, Saito J, Tohi Y, Makio H, Tanaka H, Fujita T (1999) PostMetallocenes: a New Bis(Salicylaldiminato) Zirconium Complex for Ethylene Polymerization. Chem. Lett. 28: 1263-1264.

[42] M Mitani, T Nakano, T Fujita (2003) Unprecedented Living Olefin Polymerization Derived from an Attractive Interaction Between a Ligand and a Growing Polymer Chain. Chem. Eur. J. 9:(11) 2396-2403.

[43] Makio H, Fujita T (2005) Propene Polymerization with Bis(phenoxy-imine) Group 4 Transition Metal Complexes. Bull. Chem. Soc. Jpn. 78: 52-66.

[44] Yoshida Y, Matsui S, Fujita T (2005) Bis(pyrrolideimine) Ti Complexes with MAO: a New Family of High Performance Catalysts for Olefin Polymerization. J. Organometal. Chem. 690: 4382-4397.

[45] Milano G, Cavallo L, Guerra G, (2002) Site Chirality as a Messenger in Chain-End Stereocontrolled Propene Polymerization. J. Am. Chem. Soc. 124: 13368-13369.

[46] Furuyama R, Saito J, Ishii SI, Mitani M, Matsui S, Tohi Y, Makio H, Matsukawa N, Tanaka H, Fujita T (2003) Ethylene and Propylene Polymerization Behavior of a Series of Bis(phenoxy-imine)Titanium Complexes. J. Mol. Cat. A: Chem. 200: 31-42.

[47] Matsui S, Mitani M, Saito J, Matsukawa N, Tanaka H, Nakano T, Fujita T (2000) PostMetallocenes: Catalytic Perfomance of New Bis(salicylaldiminato) Zirconium Complexes for Ethylene Polymerization. Chem. Lett. 5: 554-555. 
[48] Fujita T, Coates GW (2002) Synthesis and Characterization of Alternating and Multiblock Copolymers From Ethylene and Cyclopentene Macromolecules, 35: 96409647.

[49] Matsui S, Fujita T (2001) FI Catalysts: Super Active New Ethylene Polymerization Catalysts. Catal Today, 66: 63-73.

[50] Ittel SD, Johnson LK, Brookhart M (2000) Late-Metal Catalysts for Ethylene Homo-and copolymerization. Chem. Rev. 100: 1169-1203.

[51] Rieger B, Saunders Baugh L, Kacker S, Striegler S (eds) (2003) Late Transition Metal Polymerization Catalysis. Wiley-VCH, Weinheim.

[52] Tian J, Hustad PD, Coates GW (2001) A New Catalyst for Highly Syndiospecific Living Olefin Polymerization Homopolymers and Block Copolymers from Ethylene and Propylene. J. Am. Chem. Soc. 123: 5134-5135.

[53] Ahmadjo S, Zohuri GH, Damavandi S, Sandaroos R (2010) Comparative Ethylene Polymerization Using FI-like Zirconium Based Catalysts, Reac. Kinet. Mech. Cat. 101: 429-442.

[54] Liu D, Wang S, Wang H, Chen W, (2006) Trialkylaluminums: Efficient Cocatalysts for Bis(phenoxy-imine)Zirconium Complexes in Ethylene Polymerization, J. Mol. Catal. A: Chem. 246: 53-58.

[55] Hustad PD, Tian J, Coates GW, (2002) J. Am. Chem. Soc. Mechanism of Propylene Insertion Using Bis(phenoxyimine)-Based Titanium Catalysts: An Unusual Secondary Insertion of Propylene in a Group IV Catalyst System. 124: 3614-3621.

[56] Busico V, Cipullo R, Cutillo F, Friederichs N, Ronca S, Wang B, (2003) Improving the Performance of Methylalumoxane: A Facile and Efficient Method to Trap "Free" Trimethylaluminum, J. Am. Chem. Soc. 125: 12402-12403.

[57] Lamberti M, Pappalardo D, Mazzeo M, Pellecchia C (2004) Effects of the Reaction Conditions on the Syndiospecific Polymerization of Propene Promoted by Bis(phenoxyimine) Titanium Catalysts Macromol. Chem. Phys. 205: 486-491.

[58] Mazzeo M, Strianese M, Santoriello I, Pellecchia C (2006) Phenoxyaldimine and Phenoxyketimine Titanium Complexes in Propene Polymerization. A Different Effect of o-Phenoxy Halide Substituents. Macromolecules, 39: 7812-7820.

[59] Saito J, Mitani M, Mohri J, Ishii S, Yoshida Y, Matsugi T, Kojoh S, Kashiwa N, Fujita T (2001) Highly Syndio Specific Living Polymerization of Propylene Using a Titanium Complex Having Two Phenoxy-imine Chelate Ligands. Chem. Lett. 30: 576-582.

[60] Arriola DJ, Carnahan EM, Hustad PD, Kuhlman RL, Wenzel TT (2006) Catalytic Production of Olefin Block Copolymers via Chain Shuttling Polymerization. Science, 312: 714-719.

[61] Lamberti M, Pappalardo D, Zambelli A, Pellecchia C (2002) Syndiospecific Polymerization of Propene Promoted by Bis(salicylaldiminato)Titanium Catalysts: Regiochemistry of Monomer Insertion and Polymerization Mechanism. Macromolecules, 35: 658-663.

[62] Mitani M, Furuyama R, Mohri, JI, Saito J, Ishii S, Terao H, Nakano T, Tanaka H, Fujita T (2003) Syndiospecific Living Propylene Polymerization Catalyzed by Titanium 
Complexes Having Fluorine-Containing Phenoxy-imine Chelate Ligands. J. Am. Chem. Soc. 125: 4293-4305.

[63] Furuyama R, Mitani M, Mohri JI, Mori R, Tanaka H, Fujita T (2005) Ethylene/Higher $\alpha$ Olefin Copolymerization Behavior of Fluorinated Bis(phenoxy-imine)titanium Complexes with Methylalumoxane: Synthesis of New Polyethylene-based Block Copolymers, Macromolecules, 38: 1546-1552.

[64] Saito J, Suzuki Y, Makio H, Tanaka H, Onda M, Fujita T (2006) Polymerization of Higher $\alpha$-Olefins with a Bis(Phenoxyimine)Ti Complex/i-Bu3 $\mathrm{Al} / \mathrm{Ph}{ }_{3} \mathrm{CB}\left(\mathrm{C}_{6} \mathrm{~F}_{5}\right)_{4}$ : Formation of Stereo- and Regioirregular High Molecular Weight Polymers with High Efficiency. Macromolecules, 39: 4023-4031.

[65] Makio H, Kashiwa N, Fujita T, (2002) FI Catalysts: a New Family of High Performance Catalysts for Olefin Polymerization. Adv. Synth. Catal. 34: 477-493.

[66] Matsugi T, Matsui S, Kojoh S, Takagi Y, Inoue Y, Fujita T, Kashiwa N (2001) New Titanium Complexes Having Two Indolide-Imine Chelate Ligands for Living Ethylene Polymerization. Chem. Lett. 30: 566-577.

[67] Gottfried AC, Brookhart M, (2001) Living Polymerization of Ethylene Using Pd(II) $\alpha$ diimine Catalysts, Macromolecules, 34: 1140-1142.

[68] Tshuva EY, Goldberg I, Kol M (2000) Isospecific Living Polymerization of 1-Hexene by a Readily Available Nonmetallocene C2 Symmetrical Zirconium Catalyst. J. Am. Chem. Soc. 122: 10706-10707.

[69] Mitani M, Furuyama R, Mohri J, Saito J, Ishii S, Terao H, Kashiwa N, Fujita T (2002) Fluorine- and Trimethylsilyl-Containing Phenoxy-Imine Ti Complex for Highly Syndiotactic Living Polypropylenes with Extremely High Melting Temperatures. J. Am. Chem. Soc. 124: 7888-7889.

[70] Mitani M, Mohri J, Yoshida Y, Saito J, Ishii S, Tsuru K, Matsui S, Furuyama R, Nakano T, Tanaka H, Kohoj S, Matsugi T, Kashiwa N, Fujita T (2002) Living Polymerization of Ethylene Catalyzed by Titanium Complexes Having Fluorine-Containing Phenoxy-imine Chelate Ligands. J. Am. Chem. Soc. 124: 3327-3366.

[71] Zambelli A, Longo P, Pellecchia C, Grassi A (1987) Beta-Hydrogen Aabstraction and Regiospecific Insertion in Syndiotactic Polymerization of Styrene. Macromolecules, 20: 2035-2037.

[72] Hagimoto H, Shiono T, Ikeda T (2004) Supporting Effects of Methylaluminoxane on the Living Polymerization of Propylene with a Chelating (diamide)dimethyltitanium Complex. Macromol. Chem. Phys. 205: 19-26.

[73] Nakayama Y, Bando H, Sonobe Y, Fujita T (2004) Olefin Polymerization Behavior of Bis(phenoxy-imine) $\mathrm{Zr}$, $\mathrm{Ti}$, and $\mathrm{V}$ Complexes with $\mathrm{MgCl}_{2}$-Based Cocatalysts, J. Mol. Catal. A. 213: 141-150.

[74] Coates GW, Tian J, Hustad PD (2003) Bis(salicylaldiminato)Titanium Complex Catalysts, Highly Syndiotactic Polypropylene by a Chain-end Control Mechanism, Block Copolymers Containing this. US Patent 6562930.

[75] Sakuma A, Weiser MS, Fujita T (2007) Living Olefin Polymerization and Block Copolymer Formation with FI Catalyst. Polym. J. 39(3): 193-207. 
[76] Ishii SI, Saito J, Mitani M, Mohri JI, Matsukawa N, Tohi Y, Matsui S, Kashiwa N, Fujita $\mathrm{T}$ (2002) Highly Active Ethylene Polymerization Catalysts Based on Titanium Complexes Having Two Phenoxyimine Chelate Ligand. J. Macromol. Catal. 179: 11-16.

[77] Nakayama Y, Saito J, Bando H, Fujita T (2005) Propylene Polymerization Behavior of Fluorinated Bis(Phenoxy-imine) $\mathrm{Ti}$ Complexes with an $\mathrm{MgCl}_{2}$-Based Compound ( $\mathrm{MgCl}_{2}$-Supported Ti-Based Catalysts). Macromol. Chem. Phys. 206: 1847-1852.

[78] Ishii SI, Furuyama R, Matsukawa N, Saito J, Mitani M, Tanaka H, Fujita T (2003) Ethylene and Ethylene/Propylene Polymerization Behavior of Bis(Phenoxy-imine) Zr and Hf Complexes with Perfluorophenyl Substituents. Macromol. Rapid. Commun. 24: 452-456.

[79] Yasunori Y, Shigekazu M, Terunori F (2005) Bis(pyrrolide-imine) Ti Complexes with MAO: A New Family of High Performance Catalysts for Olefin Polymerization. J. Organometal. Chem. 690: 4382-4397.

[80] Zohuri GH, Damavandi S, Sandaroos R, Ahmadjo S (2010) Highly Active FI Catalyst of Bis[N-(3,5-dicumylsalicylidene)cyclohexylaminato] Zirconium(IV) Dichloride for Polymerization of Ethylene, Iran Polym. J. 19:(9) 679-687.

[81] Fujita T, Tohi Y, Mitani M, Matsui S, Saito J, Nitabaru M, Sugi K, Makio H, Tsutsui T (2005) Olefin Polymerization Catalysts, Transition Metal Compounds, Processes for Olefin Polymerization, and $\alpha$-Olefin/Conjugated Diene Copolymers. US Patent 6875718.

[82] Oleinik II, Oleinik IV, Ivanchev SS (2008) Design of Schiff Base-Like Postmetallocene Catalytic Systems for Polymerization of Olefins: VIII. Synthesis of N-(ocycloalkylphenyl) 2-Hydroxynaphthalene-1-Carbaldehyde imines. Russ. J. Org. Chem. 44:(1) 103-106.

[83] Burger BJ, Thompson ME, Cottor WD, Barcaw JE (1990) Ethylene Insertion and Beta.hydrogen Elimination for Permethylscandocene Alkyl Complexes. A Study of the Chain Propagation and Termination Steps in Ziegler-Natta Polymerization of Ethylene. J. Am. Chem. Soc. 112: 1566-1577.

[84] Bordwell F, Bausch MJ (1983) Methyl Effects on the Basicities of Cyclopentadienide and Indenide Ions and on the Chemistry of Their Transition Metal Complexes. J. Am. Chem. Soc. 105: 6188-6189.

[85] Damavandi S, Galland GB, Zohuri GH, Sandaroos R (2011) FI Zr-type Catalysts for Ethylene Polymerization. J. Polym. Res. 18: 1059-1065.

[86] Zhang J, Wang X, Jin GX (2006) Polymerized Metallocene Catalysts and Late Transition Metal Catalysts for Ethylene Polymerization. Coord. Chem. Rev. 250: 95-109

[87] Ivanchev SS, Trunov VA, Rybakov VB, Albov DV, Rogozin DG (2005) Dik Phys Chem 404:165.

[88] Sandaroos R, Damavandi S, Nazif A, Goharjoo M, Mohammadi A (2011) Highly Efficient Bis(aminotropone) Ti Catalyst for Ethylene Polymerization. Chinese Chemical Letters, 22: 213-216.

[89] Nakayama Y, Bando H, Sonobe Y, Fujita T (2004) Development of Single-site New Olefin Polymerization Catalyst Ssystems Using $\mathrm{MgCl}_{2}$-Based Activators: MAO-Free $\mathrm{MgCl}_{2}$-Supported FI Catalyst Systems. Chem. Soc. Japan, 77: 617-625. 
[90] Soga K, Uozumi T, Saito M, Shiono T (1994) Structure of Polypropylene and Poly(ethylene-co-propylene) Produced with an Alumina-Supported $\mathrm{CpTiCl}_{3} / \mathrm{Common}$ Alkylaluminium Catalyst System. Macromol. Chem. Phys. 195: 1503-1515.

[91] Satyanarayana G, Sivaram S (1993) An Unusually Stable Supported Bis(cyclopentadienyl)titanium dichloride-trialkylaluminum Catalyst System for Ethylene Polymerization. Macromolecules, 26: 4712-4714.

[92] Nakayama Y, Bando H, Sonobe Y, Kaneko H, Kashiwa N, Fujita T (2003) New Olefin Polymerization Catalyst Systems Comprised of Bis(Phenoxy-imine) Titanium Complexes and $\mathrm{MgCl}_{2}$-Based Activators. J. Cat. 21: 171-175.

[93] Hedden D, Marks TJ (1988), $\left[\left(\mathrm{CH}_{3}\right)_{5} \mathrm{C}_{5}\right]_{2} \mathrm{Th}\left(\mathrm{CH}_{3}\right)_{2}$ Surface Chemistry and Catalysis. Direct NMR Spectroscopic Observation of Surface Alkylation and Ethylene Insertion/Polymerization on $\mathrm{MgCl}_{2}$, J. Am. Chem. Soc. 110: 1647-1649.

[94] Xu R, Liu D, Wang S, Wang N, Mao B (2007) Preparation of Spherical MgCl2-Supported Bis(Phenoxy-imine) Zirconium Complex for Ethylene Polymerization. J. Mol. Catal. A. 263: 86-92.

[95] Srijumnonga S, Suttipitakwong P, Jongsomjita B, Praserthdama P (2008) Effect of Supports and Solvents on Ethylene Polymerization with Titanium Complex Consisting of Phenoxy-imine Ligands/dMMAO Catalytic System. J. Mol. Catal. A. 29: 1-7.

[96] Zhang D, Jin G (2004) Self-immobilized Titanium and Zirconium Catalysts with Phenoxy-imine Ligands for Ethylene Polymerization. X-ray Crystal Structure of Bis(N(3-t-butylsalicylidene)-4'-allyloxyanilinato) Zirconium (IV) dichloride. Applied Catalysis A: General ,262: 85-91. 